\title{
A Comparative Genomic Analysis of the Barley Pathogen Pyrenophora teres f. teres Identifies Subtelomeric Regions as Drivers of Virulence
}

\author{
Nathan A. Wyatt, ${ }^{1,2}$ Jonathan K. Richards, ${ }^{3}$ Robert S. Brueggeman, ${ }^{1,2}$ and Timothy L. Friesen ${ }^{1,2,4,+}$ \\ ${ }^{1}$ Genomics and Bioinformatics Program, North Dakota State University, Fargo, ND, U.S.A. \\ ${ }^{2}$ Department of Plant Pathology, North Dakota State University \\ ${ }^{3}$ Department of Plant Pathology and Crop Physiology, Louisiana State University Agricultural Center, Baton Rouge, LA, U.S.A. \\ ${ }^{4}$ Cereal Crops Research Unit, Red River Valley Agricultural Research Center, USDA-ARS, Fargo, ND, U.S.A.
}

Accepted 5 September 2019.

Pyrenophora teres f. teres causes net form net blotch of barley and is an economically important pathogen throughout the world. However, $P$. teres $\mathbf{f}$. teres is lacking in the genomic resources necessary to characterize the mechanisms of virulence. Recently a high-quality reference genome was generated for $P$. teres f. teres isolate $0-1$. Here, we present the reference quality sequence and annotation of four new isolates and we use the five available $P$. teres f. teres genomes for an in-depth comparison, resulting in the generation of hypotheses pertaining to the potential mechanisms and evolution of virulence. Comparative analyses were performed between all five $P$. teres f. teres genomes, examining genomic organization, structural variations, and core and accessory genomic content, specifically focusing on the genomic characterization of known virulence loci and the localization of genes predicted to encode secreted and effector proteins. We showed that 14 of 15 currently published virulence quantitative trait loci (QTL) span accessory genomic regions, consistent with these accessory regions being important drivers of host adaptation. Additionally, these accessory genomic regions were frequently found in subtelomeric regions of chromosomes, with 10 of the 14 accessory region QTL localizing to subtelomeric regions. Comparative analysis of the subtelomeric regions of $P$. teres f. teres chromosomes revealed translocation events in which homology was detected between nonhomologous chromosomes at a significantly higher rate than the rest of the genome. These results indicate that the subtelomeric accessory genomic compartments not only harbor most of the known virulence loci but, also, that these regions have the capacity to rapidly evolve.

\footnotetext{
${ }^{\dagger}$ Corresponding author: T. L. Friesen; timothy.friesen@ars.usda.gov
}

Funding: This research was supported by the North Dakota Barley Council, National Science Foundation grant number 1759030, and National Institute of Food and Agriculture-AFRI grant number 2018-67014-28491.

*The $\boldsymbol{e}$-Xtra logo stands for "electronic extra" and indicates that four supplementary files are published online.

The author(s) declare no conflict of interest.

This article is in the public domain and not copyrightable. It may be freely reprinted with customary crediting of the source. The American Phytopathological Society, 2020.
Keywords: barley, fungal pathogen, Pyrenophora teres, comparative genomics, effector biology, genome assembly

The intimate process of coevolution between plants and their pathogens is often depicted as a form of trench warfare in which pathogens evolve to manipulate the host, leading to the acquisition of nutrients and, in response, selection pressure is placed on the plant to develop mechanisms to resist the pathogen (Stahl and Bishop 2000). Plants have evolved an innate immune system that recognizes and responds to microbes that successful pathogens must overcome (Cook et al. 2015; Jones and Dangl 2006). This physical interaction of a pathogen with its host often occurs through a set of small secreted proteins (SSPs) termed effectors.

Pathogen effectors have evolved to manipulate the host defense response to the benefit of the pathogen, but these effectors also provide targets for plant recognition of the pathogen (Bialas et al. 2018). The function of a pathogen effector is specific to the pathogen's lifestyle and mode of nutrient acquisition. Obligate biotrophic pathogens typically invade host tissue in a manner designed to evade host recognition to gain nutrients from living tissue. Obligate biotrophs often develop haustoria that are appendages of fungal hyphae used to invaginate plant cells to serve as feeding structures and effector secretion hot spots (Perfect and Green 2001). Conversely, other pathogens, often classified as necrotrophs, can gain nutrients from dead or dying tissue resulting from pathogen-induced programmed cell death of plant cells and have evolved mechanisms to deal with the various aspects of the plant defense response (Liu et al. 2012b, 2016). Between these two models is a spectrum of fungi, often classified as hemibiotrophic, that begin plant colonization in a manner similar to a biotrophic or endophytic interaction, referred to as the biotrophic or symptomless phase, in which evasion of plant recognition is important. The symptomless or biotrophic phase is followed by a transition to the necrotrophic phase, characterized by inducing host cell death, colonization, and eventual sporulation (Vleeshouwers and Oliver 2014).

Effector discovery is hindered by a lack of homology to known proteins and the association of genes that encode effectors with low-complexity repeat-rich genomic compartments that are drivers of rapid evolutionary adaptation (Dong et al. 2015; Faino et al. 2016; Raffaele and Kamoun 2012). Pathogens must be able to quickly modify or lose effectors that are co-opted by the host, resulting in effector genes that can be highly polymorphic between members of the same species 
(Cook et al. 2015). Low-complexity regions that are rich in repeats and harbor transposable elements (TEs) are thought to be dynamic compartments involved in rapid evolution, as compared with the more-conserved stable gene-dense compartments. Pathogen effector genes often reside in these lowcomplexity regions and, consequently, are affected by increased structural polymorphism, point mutagenesis, and diversifying selection that are common to these genomic compartments (de Jonge et al. 2013; Dong et al. 2015; Faino et al. 2016; Möller and Stukenbrock 2017; Raffaele et al. 2010; Rouxel et al. 2011).

Generally, in fungi, the lack of available sequence data has been attributed to the difficulties and costs of sequencing and assembling genomes (Thomma et al. 2016). The Pacific Biosciences (PacBio) single molecule real-time (SMRT) sequencing platform is capable of read lengths of up to $60 \mathrm{~kb}$, allowing for the sequencing and assembly of full microbial genomes containing large repetitive elements (Goodwin et al. 2016; Thomma et al. 2016). In recent years, SMRT sequencing has been used to obtain complete genome sequences of a number of fungal plantpathogen species, demonstrating its utility for fungal plantpathogen genomics (Derbyshire et al. 2017; Faino et al. 2015; Richards et al. 2018; Thomma et al. 2016; van Kan et al. 2017; Wyatt et al. 2018). Finishing fungal genomes opens the door to identifying all the genes in the genome, including previously difficult-to-identify effector genes residing in low-complexity regions. When multiple isolates of the same species can be fully sequenced, the full gene repertoires of the species can be compared and characterized, termed the pan genome. (Hurgobin and Edwards 2017; Tettelin et al. 2005; Vernikos et al. 2015). This pan genome defines the entire genomic repertoire of a given taxonomic clade and accounts for all possible lifestyle processes of the organisms being observed. Pan genomes are further defined by their core genomes, representing genes common to all individuals, and their accessory genomes, representing genes that are unique to individuals within the clade. Core genomes often encode proteins associated with basic biological aspects of the entire clade, whereas accessory genomes are thought to encode genes involved in niche adaptation. The intraspecific gene content of the accessory genome is of particular interest to plant-microbe interactions, given that the genes responsible for virulence are often not shared among all individuals of a species (Croll and McDonald 2012). With the decreased cost of sequencing technology, it has become possible to sequence many individuals of a species to compare intraspecific gene content and structural variation. These comparative studies have been done for a number of bacterial species as well as some well-studied crop species. Most recently, pan-genome analyses have been conducted in the fungal plant-pathogen species Zymoseptoria tritici (Plissonneau et al. 2018), Pyrenophora tritici-repentis (Moolhuijzen et al. 2018), and Parastagonospora nodorum (Syme et al. 2018a).

Net form net blotch (NFNB) is a stubble-born foliar disease of barley (Hordeum vulgare) induced by the fungal pathogen Pyrenophora teres f. teres. Typical disease losses due to NFNB have ranged between 10 and $40 \%$, with the potential for complete yield loss given environmental conditions favorable to the pathogen, namely, wide planting of a susceptible cultivar and high humidity or rainfall (Mathre et al. 1997). P. teres f. teres infection on a susceptible host results in dot-like lesions on the leaf, progressing to longitudinal striations, and, finally, the netlike pattern from which the disease gets its name. Necrotrophic effectors (NEs) were shown to be an important component of the P. teres f. teres infection cycle (Liu et al. 2015), similar to the closely related species $P$. nodorum and $P$. tritici-repentis, which also employ NEs to induce NE triggered susceptibility (NETS) (Faris et al. 2013; Friesen and Faris 2010). In addition to NETS, dominant resistance has also been identified, in a number of barley backgrounds, that follow a gene-for-gene model. The presence of both dominant resistance and dominant susceptibility and the discovery of NEs illustrates the complicated interaction at play (Koladia et al. 2017; Liu et al. 2011, 2012a, 2015). As of yet, no effector genes have been cloned and characterized in P. teres $\mathrm{f}$. teres and, therefore, the mechanism of virulence or pathogenicity is still poorly understood.

Adding to the complexity of $P$. teres f. teres virulence is the diversity observed in both local and global pathogen populations. Host genotype specificity was first observed in a set of Australian P. teres f. teres isolates (Khan and Boyd 1969), and biparental pathogen mapping populations have been an important tool used to associate genomic loci of $P$. teres $\mathrm{f}$. teres isolates with host-specific virulence and avirulence (Beattie et al. 2007; Lai et al. 2007; Liu et al. 2011; Koladia et al. 2017; Shjerve et al. 2014; Weiland et al. 1999). Currently published mapping populations have been developed from crosses of $P$. teres $\mathrm{f}$. teres isolates $0-1 \times 15 \mathrm{~A}$, isolates $15 \mathrm{~A} \times 6 \mathrm{~A}$, and isolates FGOH04Ptt-21 $\times$ BB25 and report on a total of 15 unique genetic loci contributing to virulence leading to NFNB disease on different barley lines.

The diversity observed in $P$. teres $\mathrm{f}$. teres biparental mapping studies presents an obstacle for effector discovery in $P$. teres $\mathrm{f}$. teres isolates that have virulence associations not present in the currently published reference isolate 0-1 (Ellwood et al. 2010; Wyatt et al. 2018). With each new biparental mapping study published, unique quantitative trait loci (QTL) have been identified on common cultivars located in different parts of the $P$. teres f. teres genome, with very few QTL being identified in all biparental mapping studies (Koladia et al. 2017; Lai et al. 2007; Shjerve et al. 2014; Weiland et al. 1999). Given the diversity observed In previous mapping studies of avirulence and virulence, it is unlikely that a single isolate would capture a representative sample of the effectorome of $P$. teres $\mathrm{f}$. teres. To examine a broader sampling of the $P$. teres $\mathrm{f}$. teres effectorome, we used a pan-genome approach by sequencing and assembling four additional isolates, using PacBio SMRT sequencing, and annotated their genomes using RNA-seq support, following the same protocol outlined by Wyatt et al. (2018). Isolates sequenced have all been used previously in biparental mapping studies, including the two California isolates 15A (Lai et al. 2007; Shjerve et al. 2014; Weiland et al. 1999) and 6A (Shjerve et al. 2014), the North Dakota isolate FGOH04Ptt-21 (Koladia et al. 2017), and the Danish isolate BB25 (Koladia et al. 2017). Using the reference isolate 0-1 (Ellwood et al. 2010; Lai et al. 2007; Wyatt et al. 2018) and the four newly sequenced isolates, a pangenome analyses was performed on the five isolates to evaluate the diversity in genomic architecture and gene content. The genome annotations produced were used to identify chromosome structural variation and parse the effectorome of each isolate for comparison of effector diversity within P. teres $\mathrm{f}$. teres isolates to examine common and unique effectors of the species.

\section{RESULTS}

Genome sequencing, assembly, and scaffolding.

To assess genome composition and structure of $P$. teres $\mathrm{f}$. teres, we generated high quality genome assemblies, using PacBio SMRT sequencing, for isolates 15A, 6A, FGOH04Ptt21 , and BB25. These isolates were chosen due to their differing disease reactions on commonly used differential barley lines and their inclusion in previously reported genetic studies using pathogen biparental mapping populations (Koladia et al. 2017; Lai et al. 2007; Shjerve et al. 2014; Weiland et al. 1999). Sequencing results of the four new $P$. teres f. teres isolates compare favorably with previous sequencing efforts for $P$. teres $\mathrm{f}$. teres isolate $0-1$, which produced $1,148,507$ reads with average read lengths of 8,051 bp (Wyatt et al. 2018) (Table 1). 
Assemblies of the sequenced $P$. teres f. teres isolates $15 \mathrm{~A}$, 6A, FGOH04Ptt-21, and BB25 also compared favorably with the currently published $P$. teres $\mathrm{f}$. teres isolate $0-1$ assembly, having assembled into 163, 52, 42, and 112 contigs, respectively (Table 1). Scaffolding of the resulting assemblies, using the 16 linkage groups of the FGOH04Ptt-21 $\times$ BB25 linkage maps (Koladia et al. 2017), produced 12 total scaffolds for P. teres f. teres isolates 15A, 6A, and FGOH04Ptt-21 and produced 11 scaffolds for $P$. teres $\mathrm{f}$. teres isolate BB25 (Table 1). This is a reduced number of scaffolds compared with the number of linkage groups, due to assembled genomic sequence coverage across multiple linkage groups. P. teres $\mathrm{f}$. teres has previously been reported to have 12 chromosomes and the 12 and 11 scaffolds in the four newly sequenced isolates represent near full chromosomes, based on alignments to previously assembled $P$. teres f. teres genomes (Syme et al. 2018b; Wyatt et al. 2018). Interestingly, the total genome size of the P. teres $\mathrm{f}$. teres isolates ranged from 46.5 to $50.6 \mathrm{Mb}$ (Table 1). Additional assembly metrics are summarized in Table 1, with the currently published $P$. teres $\mathrm{f}$. teres isolate 0-1 assembly (Wyatt et al. 2018) shown as a reference metric for quality comparison between the four newly sequenced isolates 15A, 6A, FGOH04Ptt21 , and BB25.

\section{Genome annotation.}

To compare gene content between the five P. teres f. teres isolates, we generated high-confidence gene models using RNA sequencing data from each isolate. The total number of annotated genes ranged from 11,551 (6A) to 12,183 (15A) gene models between the five $P$. teres f. teres isolates, with RNA-seq evidence for the gene models ranging from $74.2 \%(0-1)$ to 98.8\% (FGOH04Ptt-21). P. teres f. teres isolates $0-1,15 \mathrm{~A}$, and $6 \mathrm{~A}$ were indexed, pooled, and sequenced on a single NextSeq run and isolates FGOH04Ptt-21 and BB25 were indexed, pooled, and sequenced on an additional NextSeq run. Differences in RNA-seq coverage between isolates is likely due to the increased depth of sequencing for isolates FGOH04Ptt-21 and $\mathrm{BB} 25$. The high number of genes with RNA-seq evidence in FGOH04Ptt-21 and BB25 helped to refine gene models in the genome annotations of $0-1,15 \mathrm{~A}$, and $6 \mathrm{~A}$, as the full set of gene models for all $P$. teres f. teres isolates were used to refine gene models for each individual $P$. teres f. teres genome. BUSCO analysis runs on each of the $P$. teres f.teres genomes, using the
Ascomycota gene set, identified complete genes for $97.4 \%$ of the genes for isolate $0-1,98.1 \%$ for isolate $15 \mathrm{~A}, 96.1 \%$ for isolate $6 \mathrm{~A}, 98.0 \%$ for isolate FGOH04Ptt-21, and $97.8 \%$ for isolate BB25. Consistent with genome annotations of other fungal pathogens, many predicted genes do not encode known pfam domains, with the number of genes encoding a pfam protein domain ranging between $60.6 \%(15 \mathrm{~A})$ and $62.2 \%(6 \mathrm{~A}$ and BB25) (Table 2).

Secreted proteins and secondary metabolites are important in fungal biology, specifically with how fungi interact with their environments. Plant pathogens employ these molecules as virulence factors and we therefore identified the genes encoding both secreted proteins and biosynthetic gene clusters. The total number of predicted secreted proteins for the five $P$. teres f. teres isolates ranged from $1,036(6 \mathrm{~A})$ to $1,066(15 \mathrm{~A})$ (Table 2). Total biosynthetic gene clusters identified in the five $P$. teres f. teres isolates ranged from $91(0-1)$ to 101 (6A) (Table 2). Relatively consistent numbers of each class of biosynthetic gene clusters were detected in each of the five $P$. teres f. teres isolates (Table 2).

Annotated repetitive content of the five $P$. teres f. teres genomes ranged from approximately $27.5 \%$ (15A) to approximately $35.6 \%$ (BB25) of the genome (Table 2). Analysis using Occultercut v1 (Testa et al. 2016) revealed a bipartite genome structure divided into high-complexity, gene-dense regions and low-complexity, gene-sparse regions (Fig. 1). Gene density in low-complexity regions ranged from 1.14 to 2.04 genes per megabase, and gene density in high-complexity regions ranged from 323 to 328 genes per megabase (Table 2). A previous examination of the repeat content of $P$. teres $\mathrm{f}$. teres found the most numerous identifiable TE families to be the DNA TE TclMariner and the long terminal repeat (LTR) Gypsy element, though a large proportion of annotated repeats belonged to yetunclassified repeat families (Syme et al. 2018b; Wyatt et al. 2018). Repeat elements were also annotated and compared for the five P. teres f. teres isolates in this study. Overall, the results of the repeat analysis in this study were similar to those of Syme et al. (2018b) in finding the largest proportion of annotated TEs belonging to either the DNA Tcl-Mariner TE or the LTR-Gypsy element, with the LTR-Gypsy element comprising the largest proportion in each of the five P. teres $\mathrm{f}$. teres genomes (Fig. 2). A large proportion of the annotated repeats in the five $P$. teres $\mathrm{f}$. teres isolates examined remain unclassified,

Table 1. Summary statistics for Pyrenophora teres f. teres genome assemblies

\begin{tabular}{|c|c|c|c|c|c|}
\hline Genome sequencing & $0-1$ & $15 \mathrm{~A}$ & 6A & FGOH04Ptt-21 & BB25 \\
\hline SMRT cells ${ }^{\mathrm{a}}$ & 14 & 9 & 9 & 9 & 9 \\
\hline Reads $^{\mathrm{b}}$ & $1,148,507$ & $1,191,458$ & 952,789 & $1,010,420$ & $1,145,857$ \\
\hline Mean read length & 8,051 & 8,674 & 7,227 & 9,927 & 7,666 \\
\hline Coverage & 199 & 222 & 148 & 216 & 189 \\
\hline \multicolumn{6}{|l|}{ Assembly statistics } \\
\hline Total genome size $(\mathrm{Mb})$ & 46.5 & 45.3 & 48.6 & 49.7 & 50.6 \\
\hline Scaffolds ${ }^{c}$ & 12 & 12 & 12 & 12 & 11 \\
\hline Markers $^{\mathrm{d}}$ & 648 & 369 & 369 & 369 & 369 \\
\hline Scaffolded bases (Mb) & 42.4 & 36.4 & 46.3 & 47.6 & 46.6 \\
\hline Percent scaffolded bases & $91.1 \%$ & $80.4 \%$ & $95.2 \%$ & $95.8 \%$ & $92.1 \%$ \\
\hline N50 scaffolds $(\mathrm{Mb})^{\mathrm{e}}$ & 4.163 & 2.996 & 4.076 & 4.128 & 5.743 \\
\hline L50 scaffolds ${ }^{\mathrm{f}}$ & 6 & 6 & 6 & 5 & 4 \\
\hline Prescaffolding contigs $\mathrm{g}$ & 85 & 163 & 52 & 42 & 115 \\
\hline N50 contigs $(\mathrm{Mb})$ & 1.730 & 0.769 & 3.608 & 4.128 & 3.759 \\
\hline Unscaffolded contigs & 42 & 74 & 36 & 16 & 55 \\
\hline
\end{tabular}

a The number of Pacific Biosciences RSII instrument SMRT cells used to sequence each $P$. teres f. teres isolate.

b Total corrected reads generated and input into the Canu assembly program.

c Number of scaffolds generated utilizing the established genetic map (Koladia et al. 2017).

d Number of markers used to establish scaffolds.

e Length of the smallest scaffold in an ordered set of scaffolds corresponding to $50 \%$ of the genomes total size.

f Smallest number of scaffolds whose length equals $50 \%$ of the genome total size.

$\mathrm{g}$ The total number of assembled ungapped contigs. 
as was also previously noted by Syme et al. (2018b) (Fig. 2). Numbers of annotated repetitive elements in the five examined genomes were consistent, although isolate $15 \mathrm{~A}$ had consistently lower numbers of annotated repeats, likely due to the lower quality of assembly relative to isolates 0-1, 6A, FGOH04Ptt-21, and BB25 (Fig. 2; Table 1).

\section{Comparative pan-genome analysis.}

To examine macro synteny between $P$. teres f. teres isolates, the four newly sequenced isolates, 15A, 6A, FGOH04Ptt-21, and $\mathrm{BB} 25$, were aligned to the reference 0-1 genome. A high degree of collinearity was observed between the reference isolate $0-1$ and isolates $15 \mathrm{~A}, 6 \mathrm{~A}$, and FGOH04Ptt-21, along the 12 established chromosomes (Fig. 3). The alignment between reference isolate $0-1$ and isolate $\mathrm{BB} 25$ showed an apparent chromosome fusion between chromosomes 1 and 2 in the BB25 isolate (Fig. 4). The fusion of $P$. teres $\mathrm{f}$. teres isolate BB25 chromosomes 1 and 2 also generated a small mini-chromosome comprised of the end of the two chromosomes. It has been previously shown that $P$. teres $\mathrm{f}$. teres chromosomes 1 and 2 share synteny along the entire length of $P$. tritici-repentis chromosome 1 (Syme et al. 2018b). Therefore, the genomes of reference isolate $0-1$ and $\mathrm{BB} 25$ were aligned to the $P$. triticirepentis isolate M4 genome to assess the relatedness of the chromosome 1 and 2 fusion in BB25. The pattern of synteny remained relatively consistent between $P$. teres f. teres isolates 0-1 and BB25 compared with P. tritici-repentis isolate M4 (Fig. 4).
We interpret this to mean that the isolate BB25 chromosome fusion is a recent event and not the result of ancestral inheritance or an interspecies hybridization event. A total of 87,189 single nucleotide polymorphisms (SNPs) were identified between $P$. teres f. teres reference isolate $0-1$ and the four newly sequenced $P$. teres f. teres isolates $15 \mathrm{~A}, 6 \mathrm{~A}$, FGOH04Ptt21 , and BB25, for use in principal component analysis (PCA) (Fig. $5 \mathrm{H}$ ). The first principal component accounted for $38 \%$ of the variability and the second principal component accounted for $26 \%$ of the variability. These results indicate that substantial genetic differentiation exists between isolates, except for 0-1 and FGOH04Ptt-21 clustering closer together.

To assess shared and unique protein functions of the five $P$. teres $\mathrm{f}$. teres isolates, 0-1, 15A, 6A, FGOH04Ptt-21, and BB25, proteins were clustered into homologous families called orthogroups, using the program Orthofinder (Emms and Kelly 2015). The total number of nonredundant protein family orthogroups identified was 12,073 . Of the 12,073 orthogroups $10,444(86.5 \%)$ were found to be shared among all five $P$. teres f. teres genomes and constitute the core genome. A total of 10,161 of the 10,444 core orthogroups represented single copy orthogroups with each $P$. teres f. teres isolate represented, leaving 283 multicopy orthogroups with shared and unique gene family expansions (Supplementary File S1). Of the 1,629 proteins resulting from the accessory genome, 750 proteins were found to be shared between at least two isolates and 879 proteins were only present in one of the five P. teres f. teres

Table 2. Summary statistics for Pyrenophora teres f. teres genome annotations

\begin{tabular}{|c|c|c|c|c|c|}
\hline Isolate & 0-1 & $15 \mathrm{~A}$ & $6 \mathbf{A}$ & FGOH04Ptt-21 & BB25 \\
\hline Genes $^{\mathrm{a}}$ & 11,573 & 12,183 & 11,551 & 11,557 & 11,986 \\
\hline Mean gene length (bp) & 1,621 & 1,643 & 1,616 & 1,633 & 1,634 \\
\hline Mean protein length (aa) & 476 & 477 & 470 & 477 & 477 \\
\hline Mean gene density $\left(\mathrm{Mb}^{-1}\right)$ & 248 & 251 & 222 & 217 & 220 \\
\hline RNA evidence $(100 \% \text { coverage })^{b}$ & $74.23 \%$ & $77.80 \%$ & $78.11 \%$ & $98.75 \%$ & $94.96 \%$ \\
\hline \multicolumn{6}{|l|}{ Protein functions $\mathrm{c}^{\mathrm{c}}$} \\
\hline$\%$ Proteins with PFAM domain & 62.1 & 60.6 & 62.2 & 62.2 & 61.2 \\
\hline Predicted secreted proteins ${ }^{\mathrm{d}}$ & 1039 & 1066 & 1036 & 1053 & 1062 \\
\hline Small secreted proteins $(<50 \mathrm{kDa})$ & 562 & 589 & 575 & 570 & 583 \\
\hline Apoplastic proteins ${ }^{\mathrm{e}}$ & 540 & 570 & 551 & 563 & 572 \\
\hline Effectors ${ }^{f}$ & 197 & 205 & 201 & 207 & 201 \\
\hline \multicolumn{6}{|l|}{ Genome repeats } \\
\hline Percent repetitive content ${ }^{\mathrm{g}}$ & $31.90 \%$ & $27.50 \%$ & $34.30 \%$ & $31.80 \%$ & $35.60 \%$ \\
\hline Low GC\% peak ${ }^{\mathrm{h}}$ & $32.10 \%$ & $30.50 \%$ & $31.00 \%$ & $32.10 \%$ & $30.40 \%$ \\
\hline High GC\% peak $^{\mathrm{i}}$ & $51.60 \%$ & $51.60 \%$ & $51.60 \%$ & $51.60 \%$ & $51.60 \%$ \\
\hline Low-complexity gene density (genes/Mb) ${ }^{\mathrm{j}}$ & 2.04 & 1.14 & 1.23 & 1.2 & 1.28 \\
\hline High-complexity gene density $\left(\right.$ genes/Mb) ${ }^{\mathrm{k}}$ & 328 & 323 & 328 & 328 & 323 \\
\hline \multicolumn{6}{|l|}{ Biosynthetic gene clusters ${ }^{1}$} \\
\hline $\mathrm{PKs}$ & 12 & 11 & 13 & 12 & 10 \\
\hline NRPs & 40 & 45 & 50 & 45 & 50 \\
\hline PK-NRP & 4 & 4 & 3 & 4 & 4 \\
\hline Terpenes & 4 & 3 & 2 & 3 & 4 \\
\hline Other & 2 & 2 & 3 & 3 & 2 \\
\hline ClusterFinder & 29 & 27 & 30 & 30 & 26 \\
\hline Total & 91 & 92 & 101 & 97 & 96 \\
\hline
\end{tabular}

a Total gene models output by the Maker2 pipeline (Holt and Yandell 2011).

b RNA evidence represents the number of gene models where full transcript length was covered by RNA-seq evidence. Isolates 0-1, 15A, and 6A were pooled and sequenced and isolates FGOH04Ptt-21 and BB25 were pooled and sequenced.

c Protein functions were predicted using Interproscan v5.25 (Jones et al. 2014).

d Proteins were determined to be secreted by the presence of a signal peptide as predicted by SignalP v4.1 (Petersen et al. 2011).

e Apoplastic proteins were predicted by the machine learning software ApoplastP v1.0 (Sperschneider et al. 2017).

${ }^{f}$ Effector protein were predicted by the machine learning software EffectorP v1.0 (Sperschneider et al. 2015).

$\mathrm{g}$ The percentage of the genome containing repetitive elements was output from RepeatMasker (Tarailo-Graovac and Chen 2009).

h Low GC\% peak represents the lowest GC\% calculated for each genome as output by OcculterCut v1 (Testa et al. 2016).

${ }^{\mathrm{i}}$ High GC\% peak represents the highest GC\% calculated for each genome as output by OcculterCut v1 (Testa et al. 2016).

j Low complexity regions were identified by OcculterCut v1 (Testa et al. 2016) and represent genomic regions with GC\% < 41.

k High complexity regions were identified by OcculterCut v1 (Testa et al. 2016) and represent genomic regions with GC\% $>41$.

1 Biosynthetic gene clusters were predicted using antiSMASH (Weber et al. 2015) and are broken down into polyketide synthases (PKs), nonribosomal peptide synthetase (NRPs), hybrid polyketide nonribosomal peptides (PK-NRPs), terpenes, other, and predicted biosynthetic clusters represented by ClusterFinder. 
isolates (Fig. 5A). The highest number of genes unique to one isolate was observed in 15A (350), and the remaining four $P$. teres $\mathrm{f}$. teres isolates $0-1,6 \mathrm{~A}$, FGOH04Ptt-21, and BB25 had 103, 118, 76, and 244 unique genes, respectively (Fig. 5A).

For further analysis, we subset the pan genome into two categories, the core genome, comprised of genes represented in all five genomes, and the accessory genome, comprised of all genes represented in four or fewer genomes. The average length of amino acid sequences was significantly different between core and accessory genes, with core genes encoding longer proteins, 484 amino acids on average, and accessory genes encoding proteins with an average amino acid length of 372 (Kruskal-Wallis test, $P<0.0001$ ) (Fig. 5D). The number of proteins containing a conserved protein domain was also found to be significantly different, with $64.2 \%$ of the genes belonging to the core genome encoding proteins containing conserved domains, whereas the proportion of accessory proteins harboring conserved domains was only $28.4 \%$ (Fig. 5C). Secreted

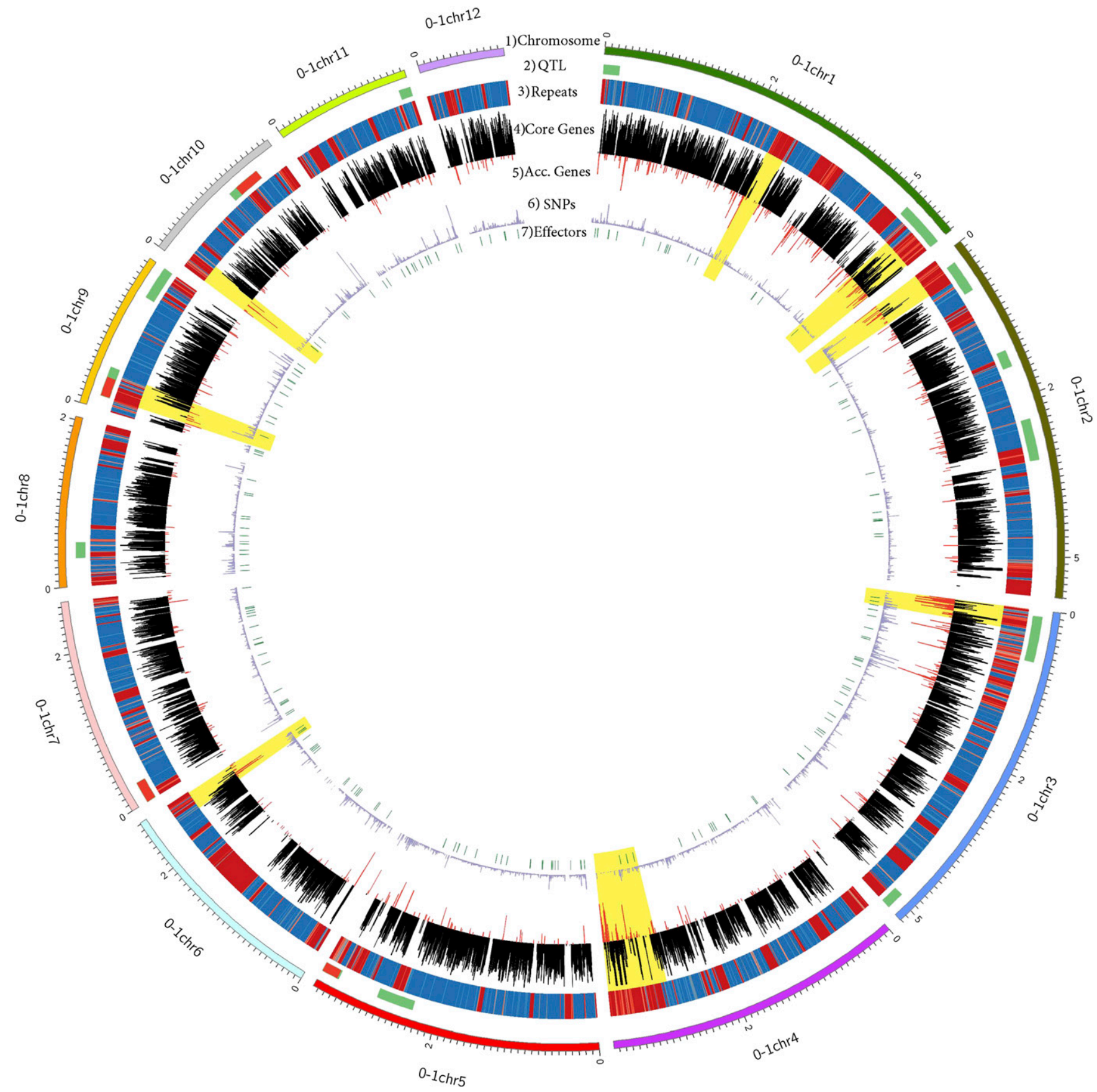

Fig. 1. A Circos plot showing the genomic landscape of Pyrenophora teres f. teres isolate 0-1. Track 1, the outermost track of the Circos plot, represents the scaffolded chromosomes of isolate 0-1. Track 2, shown in green, represents published locations of quantitative trait loci (QTL) (Lai et al. 2007; Shjerve et al 2014; Koladia et al. 2017). When multiple QTL are detected at a single locus, red is used to mark the overlapping region. Track 3 represents a heatmap of repetitive elements in the 0-1 genome in which red indicates more repetitiveness and blue denotes repeat-sparse and gene-dense regions. Track 4 represents locations and density of core genes shown in black. Track 5 represents the locations and density of accessory genes in the $0-1$ genome shown in red. Track 6 shows the density of single nucleotide polymorphisms identified between the five P. teres f. teres isolates, and track 7 shows the location of effectors predicted by EffectorP (Sperschneider et al. 2017), shown in green. Yellow blocks highlight exemplary accessory compartments in the 0-1 genome that show more repetitiveness and an increase in accessory gene content. 
proteins were examined and found to constitute a significantly higher proportion of the core genome when compared with the accessory genome, with the core genome containing $9.3 \%$ secreted proteins and the accessory genome containing $4.6 \%$ secreted proteins (Fig. 5F). Predicted effector proteins, as predicted by EffectorP (Sperschneider et al. 2016), were also examined, and no significant difference in the proportion of encoded effector proteins was found between the core and accessory gene sets, with the proportions of each being $1.7 \%$ (Fig. $5 \mathrm{G})$. TEs have been shown to be important in pathogen genome evolution and were examined for their proximity to core and accessory genes. A significant difference in TE proximity was identified with accessory genes clustering nearest TEs. On average, TEs were found to be $12.6 \mathrm{~kb}$ away from accessory genes and $26.3 \mathrm{~kb}$ away from core genes (Fig. 5E).

To assess if core and accessory genomic compartments were evolving at different rates, we examined a number of diversity statistics relative to the reference $P$. teres f. teres isolate $0-1$. We subset the 87,189 SNPs into the relative core and accessory marker sets and found that the mutation rate in accessory genes is slightly elevated, at $2.34 \mathrm{SNPs}$ per kilobase relative to core genes at 2.04 SNPs per kilobase. Additionally, we found that the mutations that do occur in accessory genes are, on average, twice as likely to be nonsynonymous (missense/silent ratio: 1.3357) relative to the core genome (missense/silent ratio: 0.9168 ). The calculated $\mathrm{pN} / \mathrm{pS}$ ratio (relative abundance of nonsynonymous and synonymous polymorphisms) for core genes was 0.29 and the $\mathrm{pN} / \mathrm{pS}$ ratio for accessory genes was 0.45 and was significantly different (Kruskal-Wallis test, $P<$ $0.0001)$. TEs were implicated in mutation by insertion into a gene or its promotor, and, given the expansion of TEs in the $P$. teres f.teres genome, we examined the rate of TE insertion in genes and their promotor regions between core and accessory gene sets. We found that the proportion of genes in the accessory genome that had a TE inserted in the promotor or coding region ranged from 24.7 to $36.8 \%$ and the core genome ranged from 4.3 to $11.4 \%$. Differences in the type of TEs involved in the insertions were observed with LTR-Gypsy, TcMarinerFot1, hAT-Restless, and DNA-academy TEs being inserted in the accessory genome at a higher proportion relative to the core genome.

Gene ontology (GO) enrichment analysis was performed on the core and accessory gene sets to further characterize putative functions of the pan genome. A total of 86 molecular function and 108 biological process GO terms were identified as significantly enriched $(P<0.05)$ within the $P$. teres f. teres core genome (Supplementary File S2). Core gene functions showing significant enrichment included basic cellular functions and metabolic processes, along with typical housekeeping functions (Supplementary File S2). GO enrichment analysis of P. teres f. teres accessory genes identified significant enrichments for functions involved in small molecule binding, including nucleotide binding, ion binding, and carbohydrate binding. Accessory genes were also enriched in gene ontologies associated with several metabolic processes as well as DNA integration, transposition, and recombination, likely driven by the proliferation of TEs in the P. teres f. teres genome detected in the genome annotation (Supplementary File S2).

We identified 283 multicopy orthogroups representing paralogs of expanded gene families ranging in size from 6 to

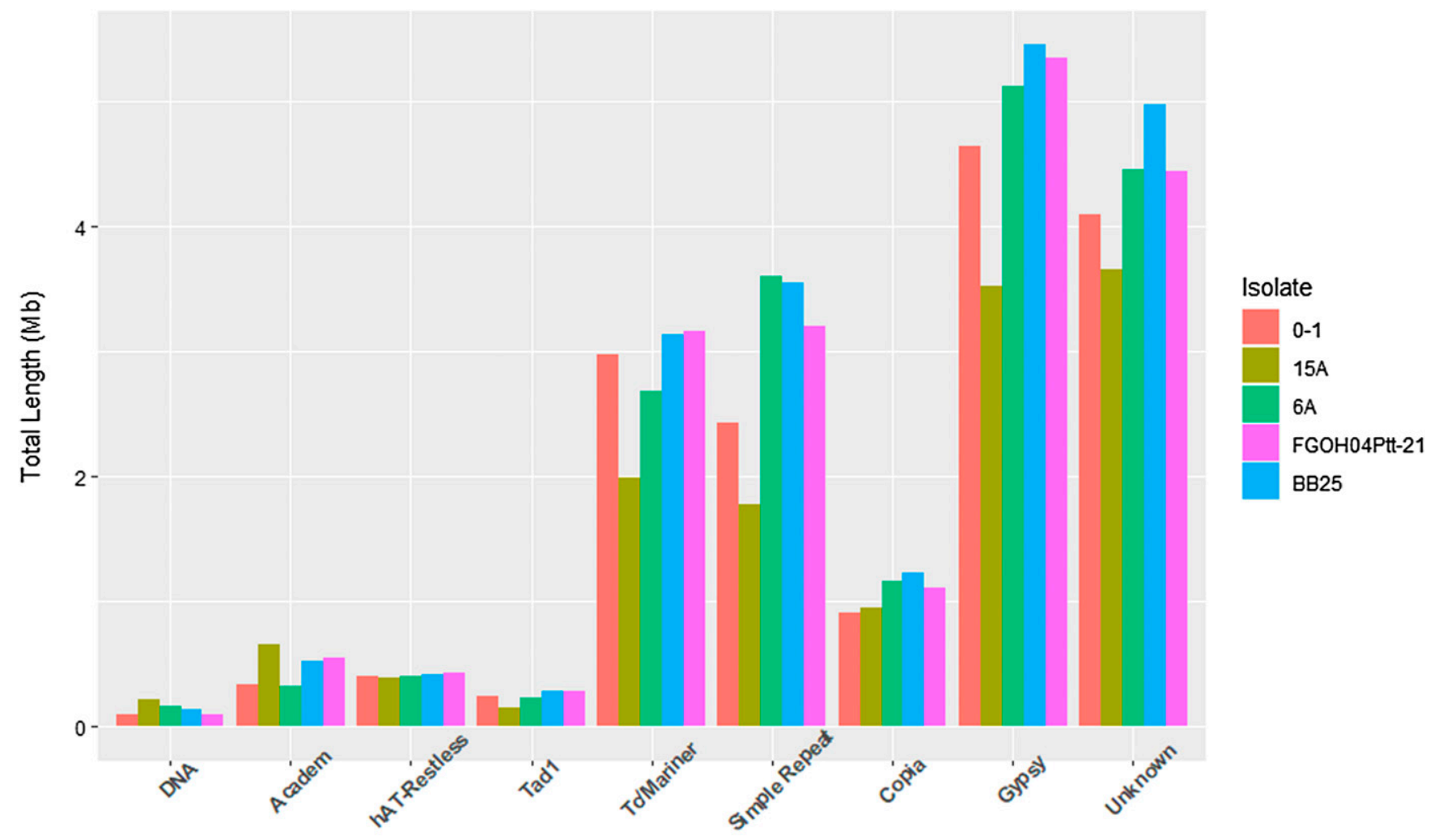

Repeat Subfamily

Fig. 2. The total length of each type of repeat subfamily expressed in megabases from each of the five Pyrenophora teres f. teres genomes. Among all five $P$. teres f. teres isolates, the most numerous repeat subfamilies are the Tc/Mariner DNA elements and the Gypsy long terminal repeat elements, though a large portion of each genome is comprised of simple repeats and largely unknown or unclassified repetitive elements. $P$. teres f. teres isolate $15 \mathrm{~A}$ shows a reduced number of repeats relative to the other four isolates, and this is attributed to uncaptured sequence. 
203 genes per orthogroup (Table 3; Supplementary File S1). Many of these expanded gene families comprise significantly different gene counts between isolates. For example, the largest family, OG0000000, contains 203 genes with per isolate counts ranging from a single protein in isolate FGOH04Ptt-21 to 104 proteins in isolate 6A (Table 3; Supplementary File S1). Several of the largest orthogroups contain genes with functions in secondary metabolite production and gene functions associated with mechanisms of transposition (Table 3 ). As an example, the annotated protein domains of OG0000000 included AMPdependent synthetase/ligase domains, phosphopantetheine binding ACP domains, and condensation domains, often found in proteins involved in the synthesis of polyketides (PKs).
Annotated protein domains of the second largest and fifth largest groups, OG0000001 and OG0000004, included retrotransposon gag domains, hAT family $\mathrm{C}$-terminal dimerization regions, and ribonuclease $\mathrm{H}$-like domains associated with retro elements. Four orthogroups belonging to a single isolate were identified and represent intragenomic duplication events. The four orthogroups were OG0000214, belonging to isolate 15A and comprising seven genes, OG0000119, belonging to isolate FGOH04Ptt-21 with 11 genes, and orthogroups OG0000098 and OG0000124, belonging to isolate $0-1$ and having 12 and 10 genes, respectively. Annotated functions of these isolatespecific orthogroups showed functions related to transposition similar to the larger expanded orthogroups.

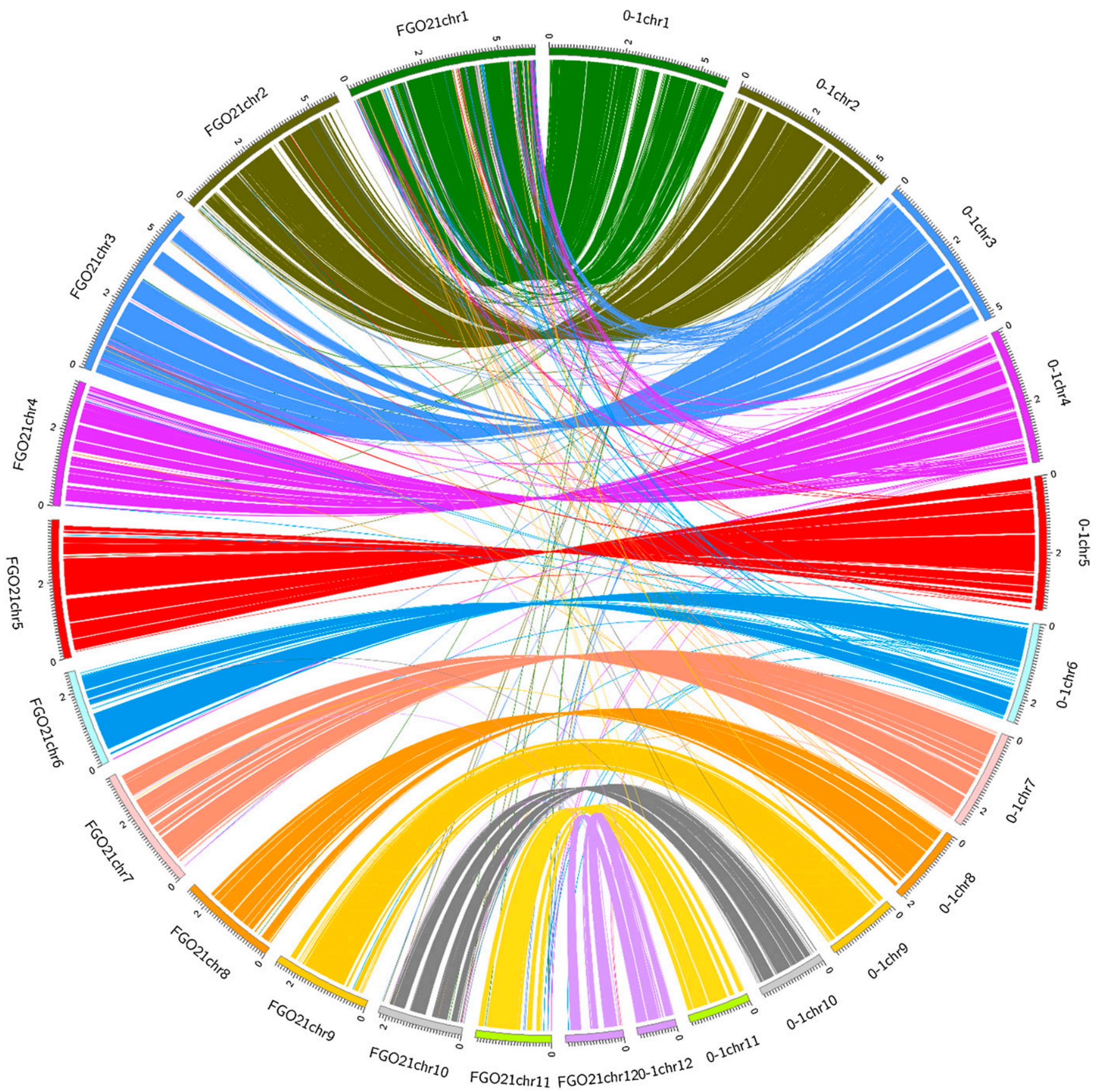

Fig. 3. Whole-genome synteny plot between Pyrenophora teres $\mathrm{f}$. teres isolates $0-1$ and FGOH04Ptt-21. Bars comprising the outer ring represent individual chromosomes labeled with size (megabases) with tick marks measuring $100 \mathrm{~kb}$. Each ribbon extending from one of the $0-1 \mathrm{chromosomes}(0-1 \mathrm{chr} \#)$ to one of the FGOH04Ptt-21 chromosomes (FGO21chr\#) represents a single 0-1 gene's best hit in the FGOH04Ptt-21 genome. Whole genome synteny plots between P. teres f. teres isolate 0-1 and isolates 15A, 6A, and BB25 can be found in Supplementary File S3. 
Effector prediction and comparative analysis.

Effector proteins are the suite of proteins employed by plant pathogens to manipulate their respective plant hosts and we anticipated the five $P$. teres $\mathrm{f}$. teres isolates in this study to have different effector repertoires based on previously published genetic analyses using these isolates (Koladia et al. 2017; Lai et al. 2007; Shjerve et al. 2014). The total number of secreted proteins for each of the five $P$. teres $\mathrm{f}$. teres isolates ranged from 1,036 secreted proteins $(6 \mathrm{~A})$ to 1,066 secreted proteins $(15 \mathrm{~A})$ and, after filtering for a size of less than $50 \mathrm{kDa}$, the number of SSPs identified ranged from $562(0-1)$ to 589 (15A) (Table 2). This set of SSPs was further analyzed using the machine learning programs ApoplastP, designed to predict proteins localized to the apoplast, and EffectorP, designed to predict effector-like proteins. ApoplastP predicted between 95.8 to $98.7 \%$ of SSPs to be localized to the apoplast and EffectorP predicted between 34.4 to $36.3 \%$ of SSPs to have effector-like protein qualities (Table 2). The difference between the proportion of SSPs predicted to be localized to the apoplast versus predicted to be effectors can be attributed to the greater specificity of EffectorP. Not all proteins secreted into the apoplast would be classified as an effector, examples would include the multitude of carbohydrate active enzymes (CAZymes) that assist in plant cell-wall degradation. Comparative analysis of the set of SSPs for the five P. teres $\mathrm{f}$. teres isolates showed that 2,728 of the 2,879 SSPs belong to the core genome (94.7\%) and only 21 SSPs were identified in a single isolate. Of the 21 SSPs unique to a single isolate, eight are predicted to be effectors by EffectorP and eight are predicted to be apoplastic by ApoplastP; however, only four of the 21 isolate-specific SSPs are both predicted to be apoplastic and effectors. Protein locus identifiers for the 21 isolate-specific SSPs can be found in the Supplementary Materials and Methods. All 21 isolate-specific SSPs were found to be expressed in planta and possibly constitute proteins important for the differential response of each isolate on different barley genotypes.

Comparisons between predicted effector proteins and secreted noneffectors showed significant differences between amino acid sequence length and proximity to TEs, with predicted effectors having shorter amino acid length and clustering in closer proximity to TEs (Kruskal-Wallis $P<0.0001$ ). GO enrichment analysis was performed on the set of SSPs, and a total of 56 molecular function and 96 biological process gene ontologies were found to be enriched $(P<0.05)$ (Supplementary File S2). Among the enriched gene ontologies for the set of SSPs were terms associated with hydrolase activity, carbohydrate binding, cell-wall degradation, and CAZymes (Supplementary File S2). GO enrichment analyses was further performed on the set of predicted effector genes to identify any effector-specific enrichment. A total of 19 molecular function and 23 biological process GO terms were found to be enriched (Supplementary File S2). Notable among the enriched effector GO terms were hydrolase activity, carbohydrate binding and degradation, regulation of ion transport, and chitin binding. Proteins with hydrolase activity and carbohydrate binding and degradation activity may have important functions in the necrotrophic infection stage of the $P$. teres $\mathrm{f}$. teres life cycle, and chitin binding proteins have been shown to be involved in protecting and hiding pathogens from plant defense responses (de Jonge et al. 2010; Liu et al. 2016; van den Burg et al. 2006) (Supplementary File S2).

\section{DISCUSSION}

Genomic plasticity in $P$. teres f. teres.

In this study, we present reference quality genome assemblies of four additional $P$. teres f. teres isolates, including 15A, 6A, FGOH04Ptt-21, and BB25 (Table 1). Each of these isolates have been included in at least one biparental mapping study that investigated the genetics of avirulence and virulence in $P$. teres f. teres because of their diverse disease reactions on differential barley lines (Koladia et al. 2017; Lai et al. 2007; Shjerve et al. 2014; Weiland et al. 1999). Whole-genome comparisons of synteny between the four newly sequenced isolates and the current $P$. teres $\mathrm{f}$. teres reference sequence $0-1$ (Ellwood et al. 2010; Wyatt et al. 2018) revealed evidence of a highly plastic

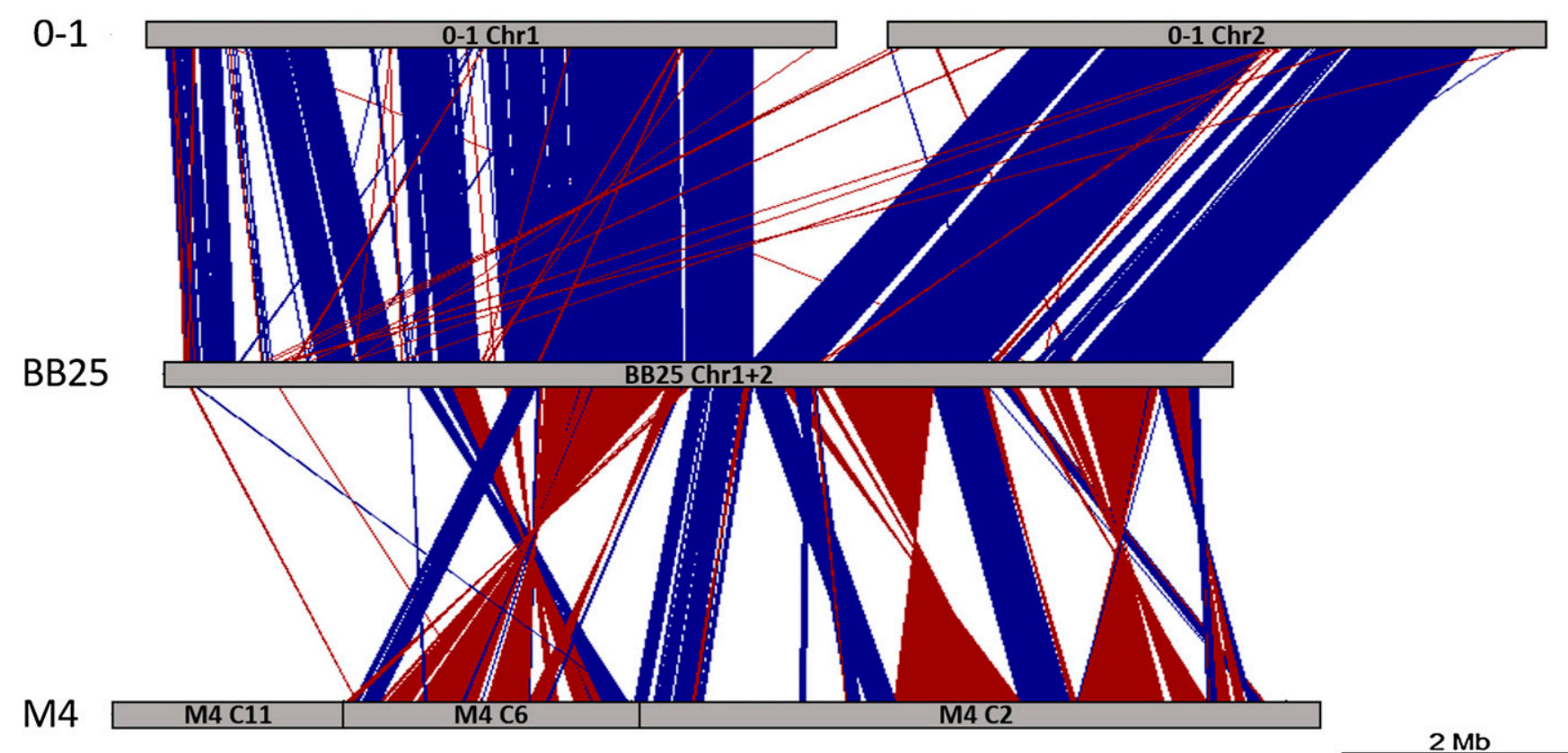

Fig. 4. Alignments between Pyrenophora teres f. teres isolate 0-1 chromosomes 1 and 2 (top), Pyrenophora teres f. teres isolate BB25 fusion chromosome 1-2 (middle), and Pyrenophora tritici-repentis isolate M4 chromosome 1 (bottom). Alignments shown are greater than $2 \mathrm{~kb}$ in length and showed at least $90 \%$ identity. Alignments shown in blue represent alignments in the forward orientation and alignments shown in red represent inversions. The pattern of synteny is conserved between the two $P$. teres f. teres isolates and both P. teres f. teres isolates show similar rearrangements relative to $P$. tritici-repentis. 
genome structure with conserved synteny among matching chromosomes, with large breaks at repeat-rich genomic compartments. These repeat-rich genomic compartments were common in subtelomeric regions of the $P$. teres f. teres chromosomes (Figs. 1 and 6). Previous genomic analysis of P. teres f. teres isolates has found more repetitive content relative to the closely related species $P$. tritici-repentis and Parastagonospora nodorum as well as the other form of the species, P. teres $\mathrm{f}$. maculata (Moolhuijzen et al. 2018; Richards et al. 2018; Syme et al. 2018b). The increase in repetitive content of $P$. teres $\mathrm{f}$. teres has facilitated a type of genomic fissuring that led to a genomic architecture in which regions of highly repetitive DNA
A

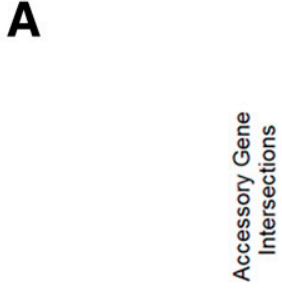

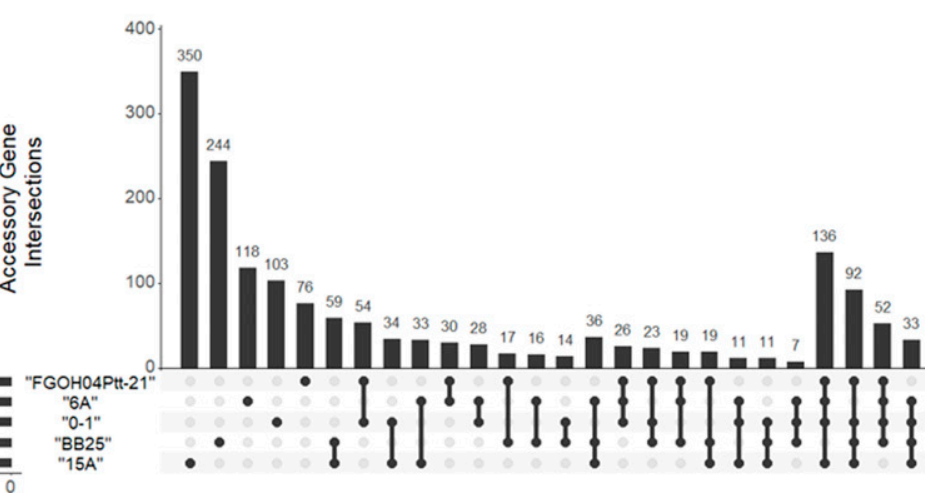

Accessory Genes Per Isolate

C

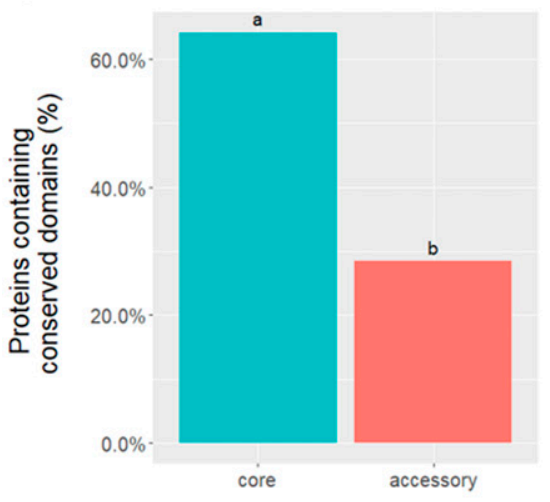

$\mathbf{F}$

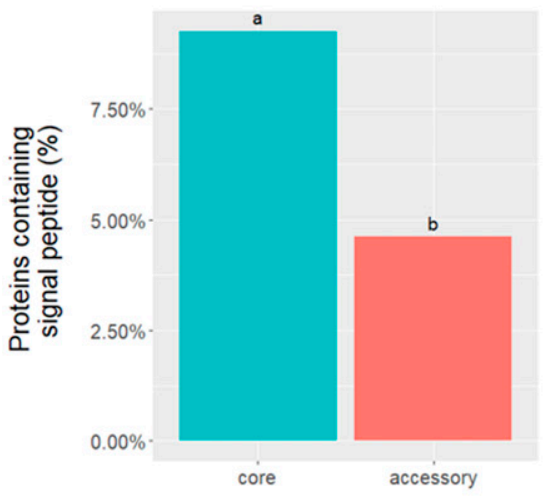

Pangenome class
D

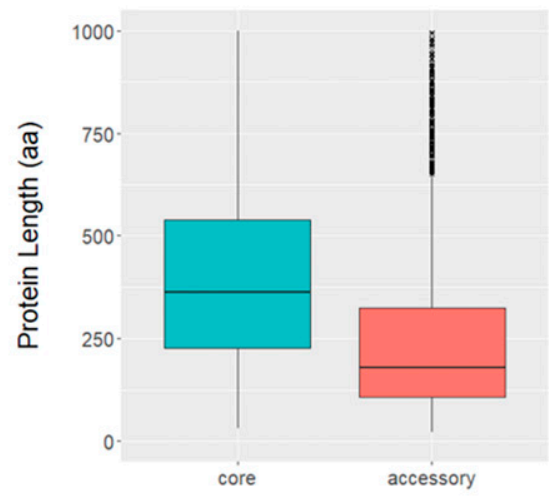

G

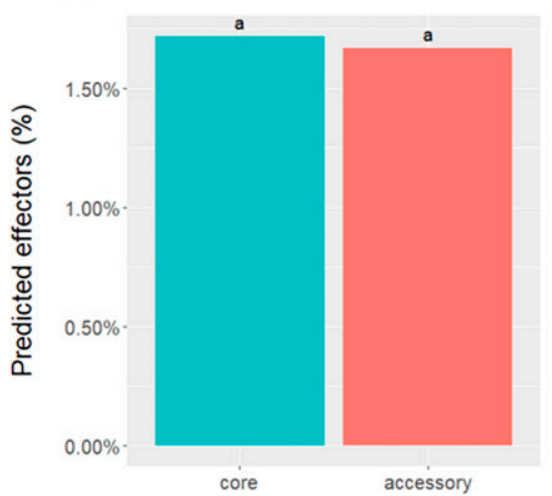

Pangenome class

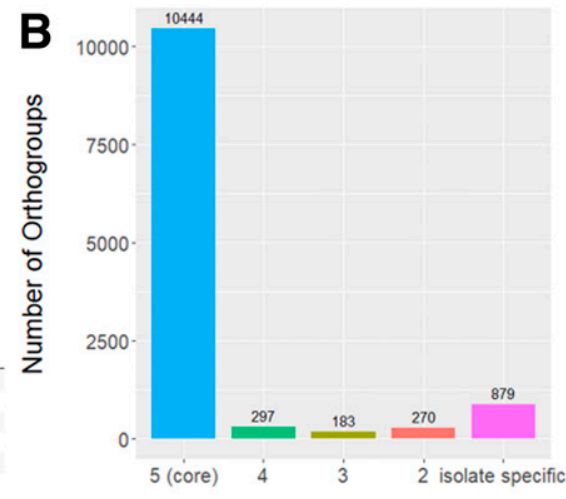

Number of Isolates

E

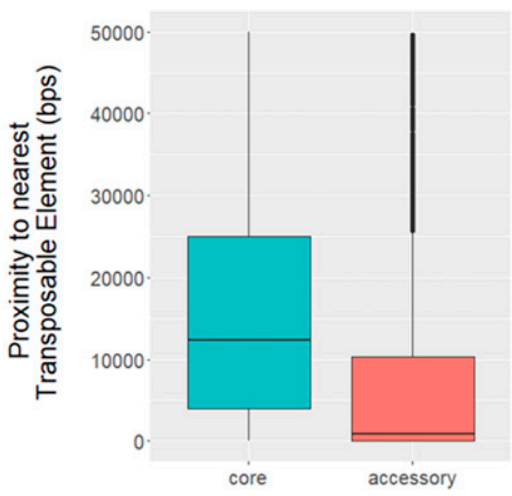

Pangenome Class

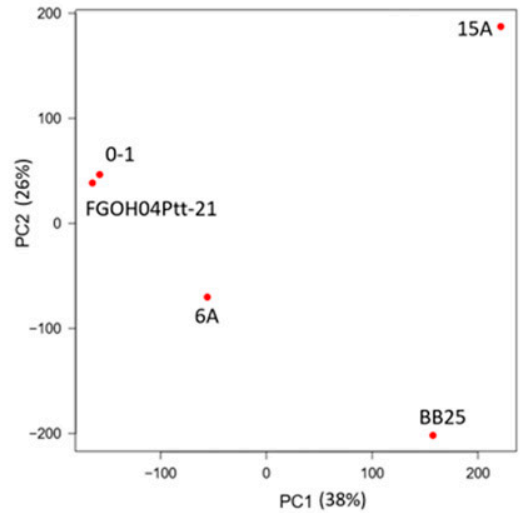

Fig. 5. Comparative genomics summary statistics assessed between different gene and protein classes in the Pyrenophora teres $\mathrm{f}$. teres genomes. A, An UpSet diagram representing the number of shared accessory orthogroups between each isolate. The bar graph on top represents the number of proteins in the group and the lower panel indicates which isolates are being compared, with dots indicating the isolate is present and lines drawn between dots to indicate the shared presence. B, The number of OrthoFinder-determined (Emms and Kelly 2015) orthogroups belonging to each isolate. Orthogroups with a protein stemming from each of the five $P$. teres $\mathrm{f}$. teres isolates were classified as core proteins and represent the largest group. Orthogroups with proteins stemming from fewer than five genomes were classified as accessory and were classified as singleton if the orthogroup was derived from just one genome. C, Different proportions of core and accessory proteins that contain conserved protein domains, with letters ' $a$ ' and ' $b$ ' above bar plots denoting significantly different groups (KruskalWallis test, $P<0.0001)$. D, The difference in protein amino acid sequence length between core and accessory proteins (Kruskal-Wallis test, $P<0.0001)$. E, The difference in the distance to the nearest transposable element compared between core and accessory proteins (Kruskal-Wallis test, $P<0.0001$ ). F, The different proportions of core and accessory proteins that contain a signal peptide, with letters 'a' and 'b' above bar plots denoting significantly different groups (KruskalWallis test, $P<0.0001)$. G, The proportion of the core and accessory proteins that are predicted effectors with no significant difference found. $\mathbf{H}$, Results of principal component analysis conducted using $>89,156$ single nucleotide polymorphisms. 
are undergoing increased evolutionary speeds relative to the more GC-equilibrated gene-rich regions of the genome (Dong et al. 2015; Faino et al. 2016; Raffaele and Kamoun 2012). Our data using the five $P$. teres $\mathrm{f}$. teres isolates examined in this study show the importance of repeat-dense accessory genomic compartments in the context of previously published diseaserelated QTL. Almost all published P. teres f. teres disease QTL span accessory compartments and are in subtelomeric regions of the genome (Figs. 1 and 6) (Koladia et al. 2017; Lai et al. 2007; Shjerve et al. 2014). This makes sense, given that these accessory compartments have been shown to be important in the host-pathogen interaction, as they are evolutionary hotspots and often harbor effector proteins (Bertazzoni et al. 2018; Croll and McDonald 2012; Franceschetti et al. 2017; Seidl and Thomma 2017; Thomma et al. 2016).

Whole-genome alignments were assessed between the five $P$. teres $\mathrm{f}$. teres isolates to examine the degree of intraspecies synteny and genome plasticity (Fig. 3; Supplementary File S3). A chromosome fusion between chromosomes 1 and 2 was discovered in $P$. teres f. teres isolate BB25 relative to the reference isolate $0-1$. Previous work examining whole-genome alignments between $P$. teres $\mathrm{f}$. teres and the closely related species $P$. tritici-repentis showed that a similar genome structure was present in P. tritici-repentis, in which P.teres f.teres chromosomes 1 and 2 have synteny along the entire length of $P$. tritici-repentis chromosome 1 (Syme et al. 2018b). The isolate BB25 fused chromosomes 1 and 2 were aligned to the newly published genomic sequence of $P$. tritici-repentis isolate M4 (Moolhuijzen et al. 2018) to determine if this chromosome fusion was a result of ancestral inheritance. It was found that, although $P$. teres f. teres chromosomes 1 and 2 were fused in isolate BB25, the genomic synteny was more conserved between other $P$. teres f. teres isolates and exhibited the same pattern of rearrangements relative to $P$. tritici-repentis (Fig. 4). We interpret this to mean that the fusion between chromosome 1 and 2 in P.teres f. teres isolate BB25 to be a recent event and not inherited through ancestry between $P$. teres f. teres and $P$. tritici-repentis. The chromosome fusion in isolate BB25 also created a short chromosome from the remainder of the two fused chromosomes. Unlike mini-chromosomes and accessory chromosomes from other plant-pathogen species, it does not appear that this short chromosome represents a disposable part of the genome, as the sequence content is present in all five $P$. teres $\mathrm{f}$. teres isolates. Chromosome length polymorphisms were identified between $P$. teres f. teres isolates $0-1$ and $15 \mathrm{~A}$ using pulse field gel electrophoresis (Ellwood et al. 2010), and it was recently reported that a chromosome fusion was detected in $P$. tritici-repentis isolate $\mathrm{M} 4$ relative to the reference P. tritici-repentis isolate Pt-1C-BFP (Moolhuijzen et al. 2018). It is possible that chromosome breakage and fusion events are a common feature of the Pyrenophora genus, resulting in chromosome length polymorphisms and chromosome fusion events and represents an interesting area for further investigation.

Chromosome synteny appears relatively conserved along matching chromosomes between P. teres f. teres isolates (Fig. 3; Supplementary File S3). Breaks in chromosome collinearity occur primarily around highly repetitive sequences in the $P$. teres f. teres genomes. Repetitive sequences and genome rearrangements between $P$. teres $\mathrm{f}$. teres isolates appeared at a higher frequency toward the ends of chromosomes within subtelomeric regions in which genomic synteny was observed to switch between matching chromosomes and all other chromosomes in the genome (Figs. 3 and 6). A possible mechanism driving these observed structural rearrangements are telomerecentromere breakage-fusion-bridge cycles (Croll et al. 2013) and recombination between nonhomologous chromosomes mediated by the high density of repetitive elements that are in accessory genomic compartments, particularly in subtelomeric regions (Argueso et al. 2008; Bzymek and Lovett 2001; Raskina et al. 2008).

Accessory genomic compartments and pathogenicity.

Previous genomic work in the closely related species Zymoseptoria tritici and $P$. tritici-repentis have examined multiple isolates within the same species in a pan-genomic approach to assess the core and accessory gene content of the species (Moolhuijzen et al. 2018; Plissonneau et al. 2018). Core gene content is representative of genes that are present in all members of the species and are likely required for the survival of the species. Accessory gene content includes genes that are absent in members of the same species and are thought to be involved in niche processes. Accessory genomic compartments have been previously shown to undergo rapid evolution relating to high mutation rates, copy number polymorphisms, and frequent ectopic recombination mediated by increased frequency of repetitive elements (Croll and McDonald 2012). These accessory genomic compartments can be as large as small chromosomes and, in the case of $Z$. tritici, include several accessory

Table 3. Orthogroup summary statistics for the five Pyrenophora teres f. teres isolates

\begin{tabular}{|c|c|c|c|c|c|c|c|}
\hline \multirow[b]{2}{*}{ OrthoGroup $^{\mathbf{a}}$} & \multicolumn{6}{|c|}{ Proteins } & \multirow[b]{2}{*}{ Associated functions ${ }^{b}$} \\
\hline & 0-1 & 15A & 6A & BB25 & FGOH04Ptt-21 & Total & \\
\hline OG0000000 & 3 & 42 & 104 & 53 & 1 & 203 & Secondary metabolite synthesis \\
\hline OG0000001 & 23 & 23 & 17 & 11 & 20 & 94 & Transposable elements \\
\hline OG0000002 & 62 & 11 & 2 & 8 & 4 & 87 & Secondary metabolite synthesis \\
\hline OG0000003 & 31 & 1 & 14 & 10 & 28 & 84 & No known function \\
\hline OG0000004 & 2 & 36 & 24 & 2 & 16 & 80 & Transposable elements \\
\hline OG0000005 & 30 & 5 & 0 & 0 & 41 & 76 & No known function \\
\hline OG0000006 & 0 & 12 & 0 & 2 & 61 & 75 & No known function \\
\hline OG0000007 & 6 & 38 & 2 & 24 & 3 & 73 & No known function \\
\hline OG0000008 & 16 & 15 & 12 & 12 & 11 & 66 & No known function \\
\hline OG0000009 & 5 & 11 & 4 & 33 & 10 & 63 & Transposable elements \\
\hline OG0000010 & 15 & 11 & 10 & 7 & 12 & 55 & No known function \\
\hline OG0000011 & 4 & 20 & 8 & 14 & 9 & 55 & Transposable elements \\
\hline OG0000012 & 11 & 16 & 9 & 10 & 8 & 54 & No known function \\
\hline OG0000013 & 10 & 11 & 9 & 12 & 11 & 53 & No known function \\
\hline OG0000014 & 10 & 16 & 0 & 17 & 10 & 53 & No known function \\
\hline OG0000015 & 10 & 13 & 8 & 11 & 8 & 50 & Epigenetic regulation \\
\hline
\end{tabular}

a OrthoGroups were output from OrthoFinder (Emms and Kelly 2015) and groups larger than 50 proteins are shown here.

b Associated functions were interpreted based on results obtained from Interproscan for the genes in each OrthoGroup. OrthoGroups with proteins lacking a conserved domain as predicted by Interproscan were labeled 'No known function'. 
chromosomes. Though we did not observe accessory chromosomes in P.teres f.teres, there is strong indication of accessory genomic regions within the genome (Fig. 1). These accessory genomic regions were frequently identified on the ends of $P$. teres f. teres chromosomes, where breaks in synteny occur and synteny between nonhomologous chromosomes occurs.
These accessory genomic regions are likely acting in a similar manner to accessory and mini-chromosomes found in other fungal species. The $P$. teres $\mathrm{f}$. teres accessory regions exhibit common characteristics that include high-density repetitive content, low-density gene content, an increased presence of accessory genes, and the decreased presence of core genes (Fig. 1).

A

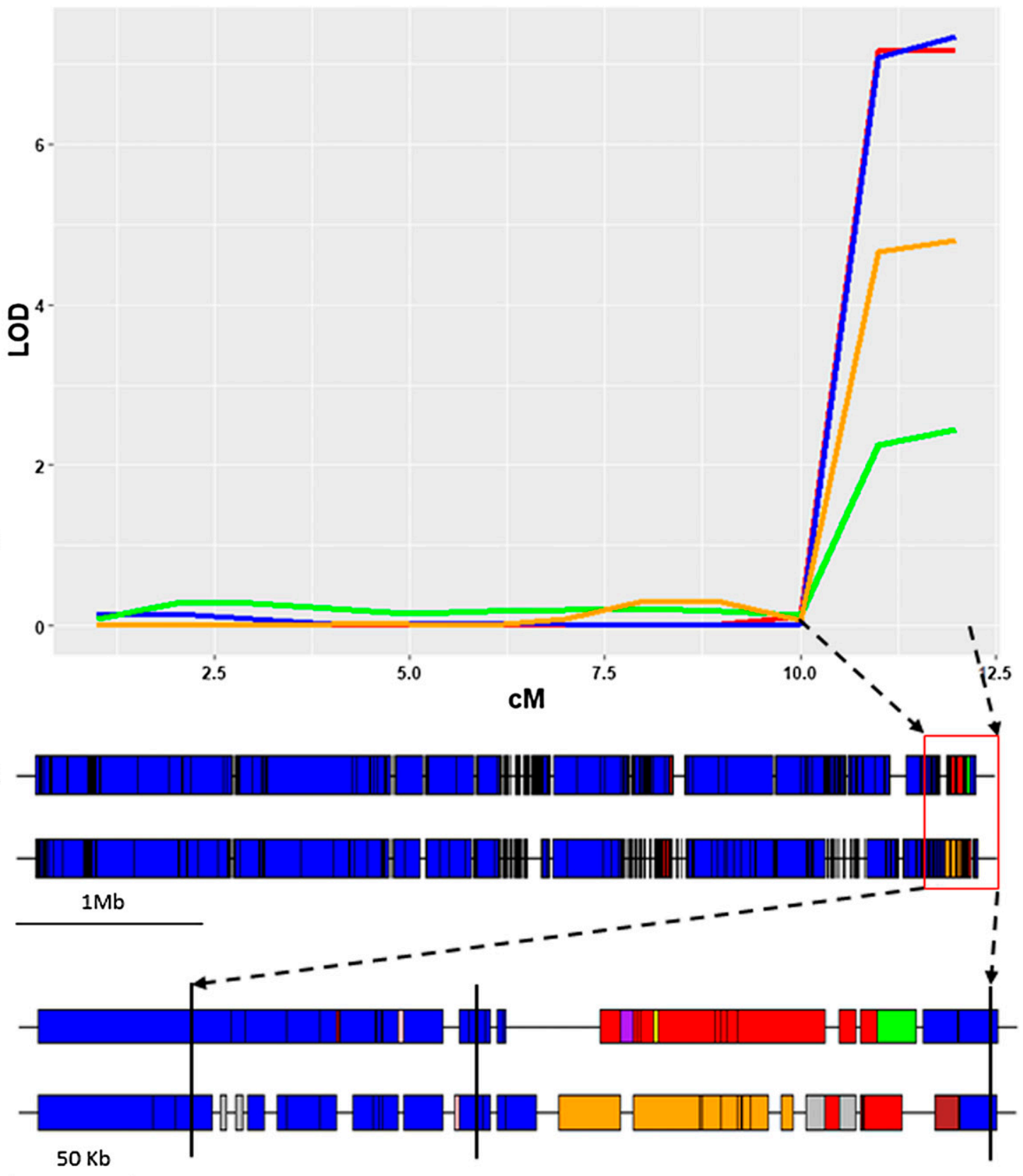

Fig. 6. A representative example (chromosome 1) of nonhomologous chromosomal exchange prevalent at the telomeres of Pyrenophora teres f. teres. A, A quantitative trait locus (QTL) analysis showing a significant association with disease reaction on the barley lines Cape, Celebration, CI9214, and Stellar. Logarithm of odds score is indicated on the $y$ axis and distance in centimorgans (cM) is indicated on the $x$ axis. Arrows directed from the QTL region in A to the red box in B designate the underlying genomic region of Pyrenophora teres f. teres chromosome 1. B, The pattern of synteny to the reference Pyrenophora teres f. teres isolate 0-1 chromosome 1 along the full length of the chromosome between isolates FGOH04Ptt-21 and BB25. Syntenic regions between matching chromosomes (i.e., chromosome 1 to chromosome 1) are shown in blue. Syntenic regions between nonmatching chromosomes are indicated with various colors. Gaps in the alignments are represented by gaps along syntenic representation of chromosome 1 . The red box at the end of chromosome 1 represents the identified QTL region, with black dashed lines with arrows extending to C, indicating the genomic region underlying the QTL region identified. C, The synteny between isolate 0-1 and FGOH04Ptt-21 and BB25, respectively. Vertical black bars indicate the location of the three associated single nucleotide polymorphism markers defining the identified QTL region. Synteny between matching chromosomes (i.e., chromosome 1 to chromosome 1) is represented in blue with the different colors representing synteny to sequences not present on isolate $0-1$ chromosome 1 . Different colors were used to identify different chromosome syntenies. Importantly, the pattern of synteny does not match between isolates FGOH04Ptt-21 and BB25, as is shown by the large red and green block of synteny in isolate FGOH04Ptt-21 and the large orange and red blocks in isolate BB25. Red blocks indicate homology to chromosome 11, green blocks indicate homology to chromosome 2 , and orange blocks indicate homology to chromosome 3 . 
Accessory genes also exhibited hallmarks of diversifying selection, as they had an increased mutational rate and increased $\mathrm{pN} / \mathrm{pS}$ ratio relative to core genes. Further adding to the increased evolutionary rate of accessory genes was the frequent intersection of accessory genes with TEs. The intersection of accessory genes and TEs makes sense in $P$. teres $\mathrm{f}$. teres, given the genomic architecture of accessory genomic compartments described above. In addition to accessory genes clustering in accessory regions, it was observed that a high proportion of secondary metabolite gene clusters were also present in accessory regions of the genome.

Genomic accessory regions and accessory chromosomes have been associated with pathogenicity in multiple plant-pathogenic species and genes implicated in virulence have been identified in these regions (Bertazzoni et al. 2018). In the plant pathogen Leptosphaeria maculans the AvrLm11 effector was identified on an accessory chromosome and conferred virulence on Brassica rapa cultivars lacking the Rlm11 gene (Balesdent et al. 2013). The Magnaporthe oryzae effector AvrPik was also identified on a small 1.6-Mb accessory chromosome (Chen et al. 2013; Luo et al. 2007). To date there have been no published effector genes in $P$. teres $\mathrm{f}$. teres, but there are currently 15 published QTL regions that have been associated with virulence and avirulence. Of the 15 published QTL, 14 reside in genomic regions that would be categorized as accessory regions and 10 of the 14 are specifically located in subtelomeric regions of the genome (Figs. 1 and 6) (Koladia et al. 2017; Lai et al. 2007; Shjerve et al. 2014; Weiland et al. 1999). This demonstrates the importance of these rapidly evolving accessory regions in the pathogenicity of $P$. teres f. teres (Figs. 1 and 6).

\section{Gene family expansions in $P$. teres f. teres.}

Gene orthology analysis of the five $P$. teres f. teres isolates revealed gene family expansions both within single and multiple $P$. teres f. teres isolates relative to other $P$. teres f. teres isolates examined in this study (Supplementary File S1). Annotated gene functions of expanded gene families within $P$. teres f. teres revolved around either genes related to TEs or genes relating to the production of secondary metabolites. The association of secondary metabolite synthesis-related proteins in the expanded gene families was a common pattern and was observed in other orthologous groups, often with a single isolate contributing the majority of the associated homologs (Supplementary File S1). Interestingly, the gene family expansions involving proteins related to secondary metabolite synthesis were present in differing numbers in the five $P$. teres $\mathrm{f}$. teres isolates, with some clusters being absent from isolates. These secondary metabolite orthogroups may represent nichespecific secondary metabolites. Further, QTL regions overlap predicted secondary metabolite clusters, pointing to their possible involvement in the disease cycle of $P$. teres $\mathrm{f}$. teres. Earlier research on $P$. teres noted the production of phytotoxic molecules that contributed to the disease as they were associated with chlorosis (Bach et al. 1979; Smedegård-Petersen 1977; Coval et al. 1990; Keon and Hargreaves 1983). A recent analysis comparing the number of biosynthetic gene clusters identified between the two forms of P. teres (f. teres versus $f$. maculata), using Australian isolates P. teres f. teres W1-1 and $P$. teres f. maculata isolate SG1, found significantly more biosynthetic gene clusters in the $P$. teres f. teres isolate (97 total biosynthetic gene clusters) (Syme et al. 2018b). Results of the current study correlate well with that of Syme et al. (2018b) and establish that $P$. teres f. teres possesses a wide array of biosynthetic gene clusters (Table 2). P. teres f. teres biosynthetic gene clusters and their interaction during infection remain an important and unexplored area of research. While further examination of $P$. teres $\mathrm{f}$. teres biosynthetic gene clusters is needed, our results confirm that $P$. teres f. teres possesses an enormous capacity to produce biologically active secondary metabolites (Coval et al. 1990; Smedegård-Petersen 1977; Syme et al. 2018b).

The second notable observation of the gene orthology analysis was the presence of TE-related proteins in the expanded gene families. Protein domains found in the top expanded gene families included the retrotransposon gag domain, hAT family $\mathrm{C}$-terminal dimerization region, and the ribonuclease $\mathrm{H}$-like domain. The presence of these protein domains in the identified expanded gene families adds support to previous results of annotated repetitive elements in the $P$. teres $\mathrm{f}$. teres genome. Previous examinations of the $P$. teres $\mathrm{f}$. teres repetitive content showed large repeat expansions relative to $P$. teres $\mathrm{f}$. maculata (Syme et al. 2018b).

\section{Main conclusions and prospects.}

This study presents four new near-complete genome sequences of $P$. teres $\mathrm{f}$. teres with gene model annotations and annotated repetitive elements. The four newly sequenced genomes of P. teres f. teres isolates 15A, 6A, FGOH04Ptt-21, and BB25 were compared with the published reference genome sequence of $P$. teres $\mathrm{f}$. teres isolate $0-1$ and an intraspecies pangenomic comparison was performed. Importantly, accessory genomic regions were identified in the $P$. teres f. teres genome that represent evolutionarily active genome compartments. Accessory genomic regions represented breaks in genome synteny and held higher numbers of accessory genes and TEs. This analysis has set the foundation for understanding the genomic landscape of $P$. teres $\mathrm{f}$. teres and the mechanisms involved in the evolution of this pathogen. These resources will also facilitate future research in the barley- $P$. teres $\mathrm{f}$. teres pathosystem providing a foundation for future research examining effector biology, secondary metabolites, TEs, and evolutionary population genomics.

\section{MATERIALS AND METHODS}

\section{Biological materials.}

Five P.teres f. teres isolates were used in this study, each of which has been included as a parent in a previous virulence mapping study. Isolate $0-1$ is the currently published reference genome (Ellwood et al. 2010; Wyatt et al. 2018) and is a Canadian isolate collected in Ontario (Weiland et al. 1999). Isolates collected in the United States include isolates 15A (Steffenson and Webster 1992) and 6A (Wu et al. 2003), collected in California, and isolate FGOH04Ptt-21, collected in Fargo, North Dakota (Koladia et al. 2017). Isolate BB25 is an isolate collected in Denmark (provided by L. Nistrup Jørgensen). These isolates were chosen as a result of their inclusion in previous genetic studies, as they differ in virulence and avirulence across barley lines commonly used in differential screening sets. Isolates $15 \mathrm{~A}$ and $0-1$ were first used in a biparental mapping study due to their differential reactions on Harbin barley (Weiland et al. 1999) and were later used in a biparental mapping study examining the differential reactions of these two isolates on the barley lines Tifang and Prato (Lai et al. 2007). Isolate $15 \mathrm{~A}$ was also crossed to isolate $6 \mathrm{~A}$, to generate a biparental mapping population, due to their different disease reactions on Kombar and Rika barley, with isolate 15A being virulent on Kombar but avirulent on Rika and isolate $6 \mathrm{~A}$ being avirulent on Kombar but virulent on Rika (Shjerve et al. 2014). Isolates FGOH04Ptt-21 and BB25 were crossed to create a biparental mapping population based on the differential disease responses of the isolates (Koladia et al. 2017) on barley lines Manchurian, Tifang, CI4922, Beecher, Celebration, Pinnacle, Hector, and Stellar (Koladia et al. 2017). 
Fungal tissue for DNA extraction was grown for $P$. teres $\mathrm{f}$. teres isolates 15A, 6A, FGOH04Ptt-21, and BB25 as described by Koladia et al. (2017), and high molecular-weight DNA extractions were completed following the methods outlined in Richards et al. (2018) (Supplementary Materials and Methods).

\section{Genome sequencing, assembly, and scaffolding.}

PacBio 20-kb size-selected sequencing libraries were prepared for all isolates and, then, were sequenced on a PacBio RSII instrument at the Mayo Clinic Molecular Biology Core (Rochester, MN, U.S.A.). A total of nine SMRT cells were sequenced for each of the four P.teres f. teres isolates.

Genome assemblies of the four P. teres f. teres isolates 15A, 6A, FGOH04Ptt-21, and BB25 were assembled in a similar manner to 0-1 (Wyatt et al. 2018). The Canu v1.5 assembler (Koren et al. 2017) was used with raw reads input in FASTQ format for correction, trimming, and assembly. The option ' genomeSize $=46.5 \mathrm{~m}$ ' was used, based on the P. teres f. teres reference isolate 0-1 genome size (Wyatt et al. 2018). Genome polishing of each assembly was done with Pilon v1.21 (Walker et al. 2014), using each isolate genome and each isolate sequencing read aligned to the genome in BAM file format. Contigs flagged as potential repeats or flagged as potential nonunique contigs by Canu were manually inspected and excluded.

The genetic linkage map of the biparental mapping population of FGOH04Ptt-21 × BB25 (Koladia et al. 2017) was used to scaffold the $P$. teres $\mathrm{f}$. teres isolates 15A, 6A, FGOH04Ptt-21, and BB25 with the program ALLMAPS (Tang et al. 2015). ALLMAPS takes assembled contigs and generates scaffolds based on coordinates from genetic linkage maps, optical maps, or syntenic maps. Contigs were ordered according to marker order on linkage groups with 100 'N' nucleotides inserted to represent gaps. Assembled contigs were quality checked by mapping reads back to the assembly, in order to assess collapsed or expanded repeat regions and potentially misassembled regions by manual inspection of read coverage. Contig collinearity with the linkage map was uniform, with the exception of isolate BB25, which contained a chromosome fusion that spanned two linkage groups. Reads were mapped back to the BB25 chromosome fusion in order to assess readdepth coverage across the fusion point of chromosomes 1 and 2 for confirmation of the chromosome fusion.

Genome assemblies for P. teres f. teres isolates 15A, 6A, FGOH04Ptt-21, and BB25 were submitted to NCBI GenBank and can be found under accession numbers VBVL00000000 (15A), VFEN00000000 (6A), VBVN00000000 (FGOH04Ptt$21)$, and VBVM00000000 (BB25). The reference genome for $P$. teres $\mathrm{f}$. teres isolate $0-1$ was previously submitted to NCBI GenBank and can be found under accession number NPOS00000000.

\section{RNA sequencing and genome annotation.}

RNA sequencing was done using in-planta timepoints of 48 , 72 , and $96 \mathrm{~h}$ postinoculation and a sample from liquid culture. Liquid culture and in-planta samples were collected in three replicates. Libraries were sequenced on an Illumina Nextseq at the USDA-ARS Small Grains Genotyping Center (Fargo, ND, U.S.A.) to produce 150-bp single-end reads. Illumina FASTQ files were quality checked and were trimmed to remove adapters and low-quality sequences (Supplementary Materials and Methods). Trimmed reads were aligned and assembled into transcripts following the protocol described by Pertea et al. (2016). For each of the four P. teres f. teres isolates, 15A, 6A, FGOH04Ptt-21, and BB25, RNA-seq reads were aligned to each previously assembled genome (Supplementary Materials and Methods).
Genome annotations were compiled using the Maker2 pipeline (Holt and Yandell 2011), using the same annotation process used in the generation of the $0-1$ reference annotation set (Wyatt et al. 2018) (Supplementary Materials and Methods). To evaluate the quality of assembled gene models for each $P$. teres $\mathrm{f}$. teres isolate, RNA-seq transcript coverage was analyzed with BEDtools, using the 'coverage' command (Quinlan 2014). Gene models were determined to have RNA-seq evidence if a gene model had $100 \%$ transcript coverage. Genome annotations were subjected to BUSCO v3 analysis, using the Ascomycota data set to assess annotation completeness (Simão et al. 2015) (Supplementary Materials and Methods).

RepeatModeler v1.0.11 (RepeatMasker software website) was used to de novo annotate repetitive elements within the genomes. Repetitive elements were then combined from each of the four genomes (15A, 6A, FGOH04Ptt-21, and BB25) and were added to the $P$. teres $\mathrm{f}$. teres specific repeat elements derived by Wyatt et al. (2018). The RepeatModeler P. teres f. teres repeat library was input into RepeatMasker (TarailoGraovac and Chen 2009), alongside the current release of Repbase (v22.10) (Bao et al. 2015), to soft mask identified repetitive elements and output a final annotation of repetitive elements identified in the genomes. The "buildSummary.pl" RepeatMasker script was applied to gather summary statistics for downstream analysis of repetitive elements.

\section{Protein domain prediction, detection \\ of biosynthetic gene clusters, and GO.}

Interproscan v. 5.25 (Jones et al. 2014) was used to predict protein domains and assign GO terms for each of the P.teres $\mathrm{f}$. teres isolates, 0-1, 15A, 6A, FGOH04Ptt-21, and BB25. GO terms (Ashburner et al. 2000) were examined for enrichment, using a hyper-geometric test with a false discovery rate cut-off set to 0.05 , using the R package topGO (Alexa and Rahnenfuhrer 2010). SignalP v4.1 was used to identify potential protein secretion signals under default parameters (Petersen et al. 2011) and TMHMM v2.0 was used to predict protein transmembrane domains (Krogh et al. 2001).

Biosynthetic gene clusters were detected in the five P. teres $\mathrm{f}$. teres genomes using the online analysis tool antiSMASH3.0 (Weber et al. 2015). Two analyses were run with different parameters, as described by Syme et al. (2018b). A simple analysis was first run on each of the five $P$. teres $\mathrm{f}$. teres isolates, using unannotated fasta files as input to antiSMASH3.0. Parameters used in the first analysis included the options to run 'KnownClusterBlast', 'SubClusterBlast', 'smCoG analysis', 'ActiveSiteFinder', and 'whole-genome PFAM analysis'. A second run was done, adding the analysis options 'ClusterFinder' and 'use ClusterFinder algorithm for BGC border prediction'. Parameters for the 'use ClusterFinder algorithm for BGC border prediction' option included the minimum cluster size set to 5 , the minimum number of biosynthesis-related PFAM domains set to 5, and a minimum 'ClusterFinder' probability of $80 \%$. Extra features added during the second run included 'Cluster-border prediction based on transcription factor binding sites (CASSIS)' and 'ClusterBlast' (Syme et al. 2018b). The antiSMASH program reports detected number of PKs, nonribosomal peptides (NRPs), PK-NRP hybrids, terpenes, and other (secondary metabolite-like clusters) resulting from the initial simple analysis. An additional report was also generated for ClusterFinder predicted biosynthetic gene clusters.

\section{Comparative pan-genome analysis.}

Whole-genome alignments of the scaffolded and repeat masked genome assemblies were facilitated by the MUMmer suite, using the internal programs 'nucmer' for genome alignments (Delcher et al. 2003; Marçais et al. 2018). Newly 
sequenced $P$. teres f. teres isolates 15A, 6A, FGOH04Ptt-21, and $\mathrm{BB} 25$ were aligned to the $0-1$ reference genome using the 'nucmer' program (options: -mum -mincluster 100 -minmatch 50) followed by filtering of the resulting alignment files with 'delta-filter' (options: -q -r) to remove any repetitive alignments. Each P. teres f. teres genome was subjected to analysis, using Occultercut v1, to identify clusters of high GC genedense regions relative to low GC gene-sparse regions after identifying and removing mitochondrial sequences (Testa et al. 2016). SNPs were identified by using the Harvest suite (Treangen et al. 2014) program 'parsnp' to align P. teres f. teres isolates 15A, 6A, FGOH04Ptt-21, and BB25 to the reference 0-1 assembly (Wyatt et al. 2018). SNPs were input into a PCA for the five genomes, using the $\mathrm{R}$ software package SNPRelate (Zheng et al. 2012). An additional PCA was done using only SNPs from gene-coding regions and the resulting eigen values were similar (Supplementary Materials and Methods).

The program SNPGenie was used to analyze the 0-1 genome and annotation to determine the number of synonymous and nonsynonymous sites (Nelson et al. 2015), and the program snpEff was used to calculate the number of mutations classified as synonymous or nonsynonymous (Cingolani et al. 2012). The $\mathrm{pN} / \mathrm{pS}$ ratio was calculated for both the accessory and core gene sets and was imported into $\mathrm{R}$ for testing significance using a Kruskal-Wallis test. Accessory and core genes were subset and mutations per gene per kilobase was calculated by dividing the total mutations in the accessory genes by the length of the corresponding transcripts. Accessory and core genes were checked for intersecting TEs using bedtools 'intersect' (Quinlan 2014).

Proteins were clustered into families using the program OrthoFinder (Emms and Kelly 2015). The pan genome was constructed based on OrthoFinder blastp result comparisons between the five P. teres f. teres proteomes (Emms and Kelly 2015).

\section{Effector prediction and comparative analysis.}

Effectors were predicted under the criteria of being secreted as predicted by SignalP v4.1 (Petersen et al. 2011), lacking a transmembrane domain as predicted by TMHMM v2.0 (Krogh et al. 2001), and having a molecular mass less than $50 \mathrm{kDa}$. The resulting list of SSPs was subjected to further analysis.

Further analyses were run on the set of SSPs including effector prediction using EffectorP v1.0 (Sperschneider et al. 2016), a program that incorporates machine learning to predict fungal effectors from the secretomes, using the default cut-off value. ApoplastP v1.0 (Sperschneider et al. 2017) was also run on the set of SSPs using the default cut-off value. ApoplastP $\mathrm{v} 1.0$ is a program that uses machine learning to predict apoplastic localized proteins from nonapoplastic localized proteins. SSPs were further examined for homology both between isolates and within the genome of each isolate. This was accomplished by using ncbi-blast+ 'blastp' of the amino acid sequences of each $P$.teres $\mathrm{f}$. teres SSP set and protein clustering by the program Orthofinder (Emms and Kelly 2015).

\section{Data visualization.}

Circos plots for Figures 1 and 3 were generated on a local Linux server, using perl version 5.24 (Krzywinski et al. 2009). Figure 1 heatmaps were generated with a window size of $5 \mathrm{~kb}$ and Figure 1 core and accessory genome frequency plots were graphed as percent coverage of $5-\mathrm{kb}$ genomic windows. Figure 3 ribbons represent single best matches of genes between $P$. teres f. teres isolates.

\section{ACKNOWLEDGMENTS}

The authors acknowledge D. Holmes for technical assistance and E. Stukenbrock for valuable suggestions and critical review of the manuscript.

\section{AUTHOR-RECOMMENDED INTERNET RESOURCES}

FastQC tool:

http://www.bioinformatics.babraham.ac.uk/projects/fastqc

RepeatMasker software: http://www.repeatmasker.org

\section{LITERATURE CITED}

Alexa A, and Rahnenfuhrer J. 2010. topGO: Enrichment analysis for gene ontology. R package version 2(0). Published online.

Argueso, J. L., Westmoreland, J., Mieczkowski, P. A., Gawel, M., Petes, T. D., and Resnick, M. A. 2008. Double-strand breaks associated with repetitive DNA can reshape the genome. Proc. Natl. Acad. Sci. U.S.A. 105:11845-11850.

Ashburner, M., Ball, C. A., Blake, J. A., Botstein, D., Butler, H., Cherry, J. M., Davis, A. P., Dolinski, K., Dwight, S. S., Eppig, J. T., Harris, M. A., Hill, D. P., Issel-Tarver, L., Kasarskis, A., Lewis, S., Matese, J. C., Richardson, J. E., Ringwald, M., Rubin, G. M., and Sherlock, G. 2000. Gene ontology: Tool for the unification of biology. Nat. Genet. 25:25-29.

Bach, E., Christensen, S., Dalgaard, L., Larsen, P. O., Olsen, C. E., and Smedegård-Petersen, V. 1979. Structures, properties and relationship to the aspergillomarasmines of toxins produced by Pyrenophora teres. Physiol. Plant Pathol. 14:41-46.

Balesdent, M. H., Fudal, I., Ollivier, B., Bally, P., Grandaubert, J., Eber, F., Chèvre, A. M., Leflon, M., and Rouxel, T. 2013. The dispensable chromosome of Leptosphaeria maculans shelters an effector gene conferring avirulence towards Brassica rapa. New Phytol. 198:887-898.

Bao, W., Kojima, K. K., and Kohany, O. 2015. Repbase Update, a database of repetitive elements in eukaryotic genomes. Mob. DNA 6:11.

Beattie, A. D., Scoles, G. J., and Rossnagel, B. G. 2007. Identification of molecular markers linked to a Pyrenophora teres avirulence gene. Phytopathology 97:842-849.

Bertazzoni, S., Williams, A. H., Jones, D. A., Syme, R. A., Tan, K. C., and Hane, J. K. 2018. Accessories make the outfit: Accessory chromosomes and other dispensable DNA regions in plant-pathogenic Fungi. Mol. Plant-Microbe Interact. 31:779-788.

Bialas, A., Zess, E. K., De la Concepcion, J. C., Franceschetti, M., Pennington, H. G., Yoshida, K., Upson, J. L., Chanclud, E., Wu, C.H., Langner, T., Maqbool, A. Varden, F. A., Derevnina, L., Belhaj, K., Fujisaki, K., Saitoh, H., Terauchi, R., Banfield, M. J., and Kamoun, S. 2018. Lessons in effector and NLR biology of plant-microbe systems. Mol. Plant-Microbe Interact. 31:34-45.

Bzymek, M., and Lovett, S. T. 2001. Instability of repetitive DNA sequences: The role of replication in multiple mechanisms. Proc. Natl Acad. Sci. U.S.A. 98:8319-8325.

Chen, C., Lian, B., Hu, J., Zhai, H., Wang, X., Venu, R. C., Liu, E., Wang, Z., Chen, M., Wang, B., Wang, G. L., Wang, Z., and Mitchell, T. K. 2013. Genome comparison of two Magnaporthe oryzae field isolates reveals genome variations and potential virulence effectors. BMC Genomics 14: 887.

Cingolani, P., Platts, A., Wang, L., Coon, M., Nguyen, T., Wang, L., Land, S. J., Lu, X., and Ruden, D. M. 2012. A program for annotating and predicting the effects of single nucleotide polymorphisms, SnpEff: SNPs in the genome of Drosophila melanogaster strain w1118; iso-2; iso-3. Fly (Austin) 6:80-92.

Cook, D. E., Mesarich, C. H., and Thomma, B. P. 2015. Understanding plant immunity as a surveillance system to detect invasion. Annu. Rev. Phytopathol. 53:541-563.

Coval, S. J., Hradil, C. M., Lu, H. S., Clardy, J., Satouri, S., and Strobel, G. A. 1990. Pyrenoline-A and-B, two new phytotoxins from Pyrenophora teres. Tetrahedron Lett. 31:2117-2120.

Croll, D., and McDonald, B. A. 2012. The accessory genome as a cradle for adaptive evolution in pathogens. PLoS Pathog. 8:e1002608.

Croll, D., Zala, M., and McDonald, B. A. 2013. Breakage-fusion-bridge cycles and large insertions contribute to the rapid evolution of accessory chromosomes in a fungal pathogen. PLoS Genet. 9:e1003567.

de Jonge, R., Bolton, M. D., Kombrink, A., van den Berg, G. C., Yadeta, K. A., and Thomma, B. P. 2013. Extensive chromosomal reshuffling drives evolution of virulence in an asexual pathogen. Genome Res. 23: 1271-1282.

de Jonge, R., van Esse, H. P., Kombrink, A., Shinya, T., Desaki, Y., Bours, R., van der Krol, S., Shibuya, N., Joosten, M. H., and Thomma, B. P. 2010. Conserved fungal LysM effector Ecp6 prevents chitin-triggered immunity in plants. Science 329:953-955.

Delcher, A. L., Salzberg, S. L., and Phillippy, A. M. 2003. Using MUMmer to identify similar regions in large sequence sets. Curr. Protoc. Bioinformatics 00:10.3.1-10.3.18. 
Derbyshire, M., Denton-Giles, M., Hegedus, D., Seifbarghy, S., Rollins, J., van Kan, J., Seidl, M. F., Faino, L., Mbengue, M., Navaud, O., Raffaele, S., Hammond-Kosack, K., Heard, S., and Oliver, R. 2017. The complete genome sequence of the phytopathogenic fungus Sclerotinia sclerotiorum reveals insights into the genome architecture of broad host range pathogens. Genome Biol. Evol. 9:593-618.

Dong, S., Raffaele, S., and Kamoun, S. 2015. The two-speed genomes of filamentous pathogens: Waltz with plants. Curr. Opin. Genet. Dev. 35: 57-65.

Ellwood, S. R., Liu, Z., Syme, R. A., Lai, Z., Hane, J. K., Keiper, F., Moffat, C. S., Oliver, R. P., and Friesen, T. L. 2010. A first genome assembly of the barley fungal pathogen Pyrenophora teres f. teres. Genome Biol. 11: R109.

Emms, D. M., and Kelly, S. 2015. OrthoFinder: Solving fundamental biases in whole genome comparisons dramatically improves orthogroup inference accuracy. Genome Biol. 16:157.

Faino, L., Seidl, M. F., Datema, E., van den Berg, G. C., Janssen, A., Wittenberg, A. H., and Thomma, B. P. 2015. Single-molecule real-time sequencing combined with optical mapping yields completely finished fungal genome. MBio 6:e00936-e15.

Faino, L., Seidl, M. F., Shi-Kunne, X., Pauper, M., van den Berg, G. C., Wittenberg, A. H., and Thomma, B. P. 2016. Transposons passively and actively contribute to evolution of the two-speed genome of a fungal pathogen. Genome Res. 26:1091-1100.

Faris, J. D., Liu, Z., and Xu, S. S. 2013. Genetics of tan spot resistance in wheat. Theor. Appl. Genet. 126:2197-2217.

Flor, H. H. 1971. Current status of the gene-for-gene concept. Annu. Rev. Phytopathol. 9:275-296.

Franceschetti, M., Maqbool, A., Jiménez-Dalmaroni, M. J., Pennington, H. G., Kamoun, S., and Banfield, M. J. 2017. Effectors of filamentous plant pathogens: Commonalities amid diversity. Microbiol. Mol. Biol. Rev. 81:e00066-316.

Friesen, T. L., and Faris, J. D. 2010. Characterization of the wheatStagonospora nodorum disease system: What is the molecular basis of this quantitative necrotrophic disease interaction? Can. J. Plant Pathol. 32:20-28.

Goodwin, S., McPherson, J. D., and McCombie, W. R. 2016. Coming of age: Ten years of next-generation sequencing technologies. Nat. Rev. Genet. 17:333-351.

Holt, C., and Yandell, M. 2011. MAKER2: An annotation pipeline and genome-database management tool for second-generation genome projects. BMC Bioinformatics 12:491.

Hurgobin, B., and Edwards, D. 2017. SNP discovery using a pangenome: Has the single reference approach become obsolete? Biology (Basel) $6: 21$.

Jones, J. D., and Dangl, J. L. 2006. The plant immune system. Nature 444: 323-329.

Jones, P., Binns, D., Chang, H. Y., Fraser, M., Li, W., McAnulla, C., McWilliam, H., Maslen, J., Mitchell, A., Nuka, G., Pesseat, S., Quinn, A. F., Sangrador-Vegas, A., Scheremetjew, M., Yong, S. Y., Lopez, R., and Hunter, S. 2014. InterProScan 5: Genome-scale protein function classification. Bioinformatics 30:1236-1240.

Keon, J. P. R., and Hargreaves, J. A. 1983. A cytological study of the net blotch disease of barley caused by Pyrenophora teres. Physiol. Plant Pathol. 22:321-329.

Khan, T. N., and Boyd, W. J. R. 1969. Environmentally induced variability in the host reaction of barley to net blotch. Aust. J. Biol. Sci. 22: 1237-1244.

Koladia, V. M., Richards, J. K., Wyatt, N. A., Faris, J. D., Brueggeman, R. S., and Friesen, T. L. 2017. Genetic analysis of virulence in the Pyrenophora teres f. teres population BB25 $\times$ FGOH04Ptt-21. Fungal Genet. Biol. 107:12-19.

Koren, S., Walenz, B. P., Berlin, K., Miller, J. R., Bergman, N. H., and Phillippy, A. M. 2017. Canu: Scalable and accurate long-read assembly via adaptive $k$-mer weighting and repeat separation. Genome Res. 27: 722-736.

Krogh, A., Larsson, B., von Heijne, G., and Sonnhammer, E. L. 2001. Predicting transmembrane protein topology with a hidden Markov model: Application to complete genomes. J. Mol. Biol. 305:567-580.

Krzywinski, M., Schein, J., Birol, I., Connors, J., Gascoyne, R., Horsman, D., Jones, S. J., and Marra, M. A. 2009. Circos: An information aesthetic for comparative genomics. Genome Res. 19:1639-1645.

Lai, Z., Faris, J. D., Weiland, J. J., Steffenson, B. J., and Friesen, T. L. 2007. Genetic mapping of Pyrenophora teres f. teres genes conferring avirulence on barley. Fungal Genet. Biol. 44:323-329.

Liu, Z., Ellwood, S. R., Oliver, R. P., and Friesen, T. L. 2011. Pyrenophora teres: Profile of an increasingly damaging barley pathogen. Mol. Plant Pathol. 12:1-19.
Liu, Z., Gao, Y., Kim, Y. M., Faris, J. D., Shelver, W. L., de Wit, P. J., Xu, S. S., and Friesen, T. L. 2016. SnTox1, a Parastagonospora nodorum necrotrophic effector, is a dual-function protein that facilitates infection while protecting from wheat-produced chitinases. New Phytol. 211: 1052-1064.

Liu, Z., Holmes, D. J., Faris, J. D., Chao, S., Brueggeman, R. S., Edwards, M. C., and Friesen, T. L. 2015. Necrotrophic effector-triggered susceptibility (NETS) underlies the barley-Pyrenophora teres f. teres interaction specific to chromosome 6H. Mol. Plant Pathol. 16:188-200.

Liu, Z., Zhang, Z., Faris, J. D., Oliver, R. P., Syme, R., McDonald, M. C., McDonald, B. A., Solomon, P. S., Lu, S., Shelver, W. L., Xu, S., and Friesen, T. L. 2012a. The cysteine rich necrotrophic effector SnTox1 produced by Stagonospora nodorum triggers susceptibility of wheat lines harboring Snn1. PLoS Pathog. 8:e1002467.

Liu, Z. H., Zhong, S., Stasko, A. K., Edwards, M. C., and Friesen, T. L. 2012b. Virulence profile and genetic structure of a North Dakota population of Pyrenophora teres $\mathrm{f}$. teres, the causal agent of net form net blotch of barley. Phytopathology 102:539-546.

Luo, C. X., Yin, L. F., Ohtaka, K., and Kusaba, M. 2007. The 1.6Mb chromosome carrying the avirulence gene AvrPik in Magnaporthe oryzae isolate $84 \mathrm{R}-62 \mathrm{~B}$ is a chimera containing chromosome 1 sequences. Mycol. Res. 111:232-239.

Marçais, G., Delcher, A. L., Phillippy, A. M., Coston, R., Salzberg, S. L., and Zimin, A. 2018. MUMmer4: A fast and versatile genome alignment system. PLOS Comput. Biol. 14:e1005944.

Mathre, D. E., Kushnak, G. D., Martin, J. M., Grey, W. E., and Johnston, R. H. 1997. Effect of residue management on barley production in the presence of net blotch disease. J. Prod. Agric. 10:323-326.

Möller, M., and Stukenbrock, E. H. 2017. Evolution and genome architecture in fungal plant pathogens. Nat. Rev. Microbiol. 15:756-771.

Moolhuijzen, P., See, P. T., Hane, J. K., Shi, G., Liu, Z., Oliver, R. P., and Moffat, C. S. 2018. Comparative genomics of the wheat fungal pathogen Pyrenophora tritici-repentis reveals chromosomal variations and genome plasticity. BMC Genomics 19:279.

Nelson, C. W., Moncla, L. H., and Hughes, A. L. 2015. SNPGenie: Estimating evolutionary parameters to detect natural selection using pooled next-generation sequencing data. Bioinformatics 31:3709-3711.

Perfect, S. E., and Green, J. R. 2001. Infection structures of biotrophic and hemibiotrophic fungal plant pathogens. Mol. Plant Pathol. 2:101-108.

Pertea, M., Kim, D., Pertea, G. M., Leek, J. T., and Salzberg, S. L. 2016. Transcript-level expression analysis of RNA-seq experiments with HISAT, StringTie and Ballgown. Nat. Protoc. 11:1650-1667.

Petersen, T. N., Brunak, S., von Heijne, G., and Nielsen, H. 2011. SignalP 4.0: Discriminating signal peptides from transmembrane regions. Nat. Methods 8:785-786.

Plissonneau, C., Hartmann, F. E., and Croll, D. 2018. Pangenome analyses of the wheat pathogen Zymoseptoria tritici reveal the structural basis of a highly plastic eukaryotic genome. BMC Biol. 16:5.

Quinlan, A. R. 2014. BEDTools: The Swiss-army tool for genome feature analysis. Curr. Protoc. Bioinformatics 47:11.12.1-11.12.34.

Raffaele, S., Farrer, R. A., Cano, L. M., Studholme, D. J., MacLean, D., Thines, M., Jiang, R. H., Zody, M. C., Kunjeti, S. G., Donofrio, N. M., Meyers, B. C., Nusbaum, C., and Kamoun, S. 2010. Genome evolution following host jumps in the Irish potato famine pathogen lineage. Science 330:1540-1543.

Raffaele, S., and Kamoun, S. 2012. Genome evolution in filamentous plant pathogens: Why bigger can be better. Nat. Rev. Microbiol. 10:417-430.

Raskina, O., Barber, J. C., Nevo, E., and Belyayev, A. 2008. Repetitive DNA and chromosomal rearrangements: Speciation-related events in plant genomes. Cytogenet. Genome Res. 120:351-357.

Richards, J. K., Wyatt, N. A., Liu, Z., Faris, J. D., and Friesen, T. L. 2018. Reference quality genome assemblies of three Parastagonospora nodorum isolates differing in virulence on wheat. G3 (Bethesda) 8: 393-399.

Rouxel, T., Grandaubert, J., Hane, J. K., Hoede, C., van de Wouw, A. P., Couloux, A., Dominguez, V., Anthouard, V., Bally, P., Bourras, S., Cozijnsen, A. J., Ciuffetti, L. M., Degrave, A., Dilmaghani, A., Duret, L., Fudal, I., Goodwin, S. B., Gout, L., Glaser, N., Linglin, J., Kema, G. H., Lapalu, N., Lawrence, C. B., May, K., Meyer, M., Ollivier, B., Poulain, J., Schoch, C. L., Simon, A., Spatafora, J. W., Stachowiak, A., Turgeon, B. G., Tyler, B. M., Vincent, D., Weissenbach, J., Amselem, J., Quesneville, H., Oliver, R. P., Wincker, P., Balesdent, M. H., and Howlett, B. J. 2011. Effector diversification within compartments of the Leptosphaeria maculans genome affected by repeat-induced point mutations. Nat. Commun. 2:202.

Seidl, M. F., and Thomma, B. P. H. J. 2017. Transposable elements direct the coevolution between plants and microbes. Trends Genet. 33:842-851. 
Shjerve, R. A., Faris, J. D., Brueggeman, R. S., Yan, C., Zhu, Y., Koladia, V., and Friesen, T. L. 2014. Evaluation of a Pyrenophora teres f. teres mapping population reveals multiple independent interactions with a region of barley chromosome 6H. Fungal Genet. Biol. 70:104-112.

Simão, F. A., Waterhouse, R. M., Ioannidis, P., Kriventseva, E. V., and Zdobnov, E. M. 2015. BUSCO: Assessing genome assembly and annotation completeness with single-copy orthologs. Bioinformatics 31 : 3210-3212.

Smedegård-Petersen, V. 1977. Isolation of two toxins produced by Pyrenophora teres and their significance in disease development of net-spot blotch of barley. Physiol. Plant Pathol. 10:203-211.

Sperschneider, J., Dodds, P. N., Singh, K. B., and Taylor, J. M. 2017. ApoplastP: Prediction of effectors and plant proteins in the apoplast using machine learning. New Phytol. 217:1764-1778.

Sperschneider, J., Gardiner, D. M., Dodds, P. N., Tini, F., Covarelli, L., Singh, K. B., Manners, J. M., and Taylor, J. M. 2016. EffectorP: Predicting fungal effector proteins from secretomes using machine learning. New Phytol. 210:743-761.

Stahl, E. A., and Bishop, J. G. 2000. Plant-pathogen arms races at the molecular level. Curr. Opin. Plant Biol. 3:299-304.

Steffenson, B. J., and Webster, R. K. 1992. Pathotype diversity of Pyrenophora teres $\mathrm{f}$. teres on barley. Phytopathology 82:170-177.

Syme, R. A., Martin, A., Wyatt, N. A., Lawrence, J. A., Muria-Gonzalez, M. J., Friesen, T. L., and Ellwood, S. R. 2018b. Transposable element genomic fissuring in Pyrenophora teres is associated with genome expansion and dynamics of host-pathogen genetic interactions. Front. Genet. 9:130.

Syme, R. A., Tan, K. C., Rybak, K., Friesen, T. L., McDonald, B. A., Oliver, R. P., and Hane, J. K. 2018a. Pan-Parastagonospora comparative genome analysis-effector prediction and genome evolution. Genome Biol. Evol. 10:2443-2457.

Tang, H., Zhang, X., Miao, C., Zhang, J., Ming, R., Schnable, J. C., Schnable, P. S., Lyons, E., and Lu, J. 2015. ALLMAPS: Robust scaffold ordering based on multiple maps. Genome Biol. 16:3.

Tarailo-Graovac, M., and Chen, N. 2009. Using RepeatMasker to identify repetitive elements in genomic sequences. Curr. Protoc. Bioinformatics 25: 4.10.1 4.10.14.

Testa, A. C., Oliver, R. P., and Hane, J. K. 2016. OcculterCut: A comprehensive survey of AT-rich regions in fungal genomes. Genome Biol. Evol. 8:2044-2064.

Tettelin, H., Masignani, V., Cieslewicz, M. J., Donati, C., Medini, D., Ward, N. L., Angiuoli, S. V., Crabtree, J., Jones, A. L., Durkin, A. S., Deboy, R. T., Davidsen, T. M., Mora, M., Scarselli, M., Margarit y Ros, I., Peterson, J. D., Hauser, C. R., Sundaram, J. P., Nelson, W. C., Madupu, R., Brinkac, L. M., Dodson, R. J., Rosovitz, M. J., Sullivan, S. A., Daugherty, S. C., Haft, D. H., Selengut, J., Gwinn, M. L., Zhou, L., Zafar, N., Khouri, H., Radune, D., Dimitrov, G., Watkins, K., O’Connor, K. J., Smith, S., Utterback, T. R., White, O., Rubens, C. E., Grandi, G.,
Madoff, L. C., Kasper, D. L., Telford, J. L., Wessels, M. R., Rappuoli, R., and Fraser, C. M. 2005. Genome analysis of multiple pathogenic isolates of Streptococcus agalactiae: Implications for the microbial "pangenome”. Proc. Natl. Acad. Sci. U.S.A. 102:13950-13955.

Thomma, B. P. H. J., Seidl, M. F., Shi-Kunne, X., Cook, D. E., Bolton, M. D., van Kan, J. A. L., and Faino, L. 2016. Mind the gap; seven reasons to close fragmented genome assemblies. Fungal Genet. Biol. 90:24-30.

Treangen, T. J., Ondov, B. D., Koren, S., and Phillippy, A. M. 2014. The Harvest suite for rapid core-genome alignment and visualization of thousands of intraspecific microbial genomes. Genome Biol. 15:524.

van den Burg, H. A., Harrison, S. J., Joosten, M. H., Vervoort, J., and de Wit, P. J. 2006. Cladosporium fulvum Avr4 protects fungal cell walls against hydrolysis by plant chitinases accumulating during infection. Mol. Plant-Microbe Interact. 19:1420-1430.

Van Kan, J. A., Stassen, J. H., Mosbach, A., Van Der Lee, T. A., Faino, L., Farmer, A. D., Papasotiriou, D. G., Zhou, S., Seidl, M. F., Cottam, E., Edel, D., Hahn, M., Schwartz, D. C., Dietrich, R. A., Widdison, S., and Scalliet, G. 2017. A gapless genome sequence of the fungus Botrytis cinerea. Mol. Plant Pathol. 18:75-89.

Vernikos, G., Medini, D., Riley, D. R., and Tettelin, H. 2015. Ten years of pan-genome analyses. Curr. Opin. Microbiol. 23:148-154.

Vleeshouwers, V. G., and Oliver, R. P. 2014. Effectors as tools in disease resistance breeding against biotrophic, hemibiotrophic, and necrotrophic plant pathogens. Mol. Plant-Microbe Interact. 27:196-206.

Walker, B. J., Abeel, T., Shea, T., Priest, M., Abouelliel, A., Sakthikumar, S., Cuomo, C. A., Zeng, Q., Wortman, J., Young, S. K., and Earl, A. M. 2014. Pilon: An integrated tool for comprehensive microbial variant detection and genome assembly improvement. PLoS One 9:e112963.

Weber, T., Blin, K., Duddela, S., Krug, D., Kim, H. U., Bruccoleri, R., Lee, S. Y., Fischbach, M. A., Müller, R., Wohlleben, W., Breitling, R., Takano, E., and Medema, M. H. 2015. antiSMASH 3.0-a comprehensive resource for the genome mining of biosynthetic gene clusters. Nucleic Acids Res. 43: W237-W243.

Weiland, J. J., Steffenson, B. J., Cartwright, R. D., and Webster, R. K. 1999. Identification of molecular genetic markers in Pyrenophora teres $\mathrm{f}$. teres associated with low virulence on 'Harbin'barley. Phytopathology 89: 176-181.

Wu, H. L., Steffenson, B. J., Zhong, S., Li, Y., and Oleson, A. E. 2003. Genetic variation for virulence and RFLP markers in Pyrenophora teres. Can. J. Plant Pathol. 25:82-90.

Wyatt, N. A., Richards, J. K., Brueggeman, R. S., and Friesen, T. L. 2018. Reference assembly and annotation of the Pyrenophora teres f. teres isolate 0-1. G3 (Bethesda) 8:1-8.

Zheng, X., Levine, D., Shen, J., Gogarten, S. M., Laurie, C., and Weir, B. S. 2012. A high-performance computing toolset for relatedness and principal component analysis of SNP data. Bioinformatics 28: 3326-3328. 